Article

\title{
Synthesis and Preliminary Biological Evaluation of Two Fluoroolefin Analogs of Largazole Inspired by the Structural Similarity of the Side Chain Unit in Psammaplin A
}

\author{
Bingbing Zhang ${ }^{1,+}$, Guangsheng Shan ${ }^{1,+}$, Yinying Zheng ${ }^{1,+}$, Xiaolin Yu 1,2, Zhu-Wei Ruan ${ }^{1}$, \\ Yang $\mathrm{Li}^{1}$ and Xinsheng Lei ${ }^{1,3, *}$ \\ 1 School of Pharmacy, Fudan University, 826 Zhangheng Road, Pudong Zone, Shanghai 201203, China; \\ 14211030012@fudan.edu.cn (B.Z.); 12211030043@fudan.edu.cn (G.S.); 17211030013@fudan.edu.cn (Y.Z.); \\ 13774294998@163.com (X.Y.); 13301030004@fudan.edu.cn (Z.-W.R.); 13211030007@fudan.edu.cn (Y.L.) \\ 2 College of Chemistry and Molecular Engineering, Zhengzhou University, Zhengzhou 450001, China \\ 3 Key Laboratory of Synthetic Chemistry of Natural Substances, Shanghai Institute of Organic Chemistry, \\ Chinese Academy of Sciences, Shanghai 200032, China \\ * Correspondence: leixs@fudan.edu.cn; Tel.: +86-021-51980128 \\ + These authors contributed equally to the work.
}

Received: 15 May 2019; Accepted: 28 May 2019; Published: 3 June 2019

check for updates

\begin{abstract}
Largazole, isolated from a marine Cyanobacterium of the genus Symploca, is a potent and selective Class I HDAC (histone deacetylation enzymes) inhibitor. This natural 16-membered macrocyclic depsipeptide features an interesting side chain unit, namely 3-hydroxy-7-mercaptohept-4-enoic acid, which occurs in many other natural sulfur-containing HDAC inhibitors. Notably, one similar fragment, where the amide moiety replaces the trans alkene moiety, appears in Psammaplin A, another marine natural product with potent HDAC inhibitory activities. Inspired by such a structural similarity, we hypothesized the fluoroolefin moiety would mimic both the alkene moiety in Largazole and the amide moiety in Psammaplin A, and thus designed and synthesized two novel fluoro olefin analogs of Largazole. The preliminary biological assays showed that the fluoro analogs possessed comparable Class I HDAC inhibitory effects, indicating that this kind of modification on the side chain of Largazole was tolerable.
\end{abstract}

Keywords: marine natural product; Largazole; Psammaplin A; HDAC inhibitors; luoro olefin

\section{Introduction}

The regulation of histone-tailed lysine acetylation by histone acetyltransferases (HATs) and histone deacetylases (HDACs) plays a key role in the biochemistry of life process [1]. So far, at least 18 HDAC isoforms have been discovered, including $\mathrm{Zn}^{2+}$-dependent Class I (HDAC1, 2, 3, 8), Class II (class IIa: HDAC4 , 5, 7, 9; class IIb: HDAC6, 10) and Class IV (HDAC11) [2]. Although the function of individual HDAC isoforms is not fully understood in cell and cancer biology, several pan-selective HDAC inhibitors, such as SAHA (Vorinostat), Belinostat, Panobinostat, Chidamide and Romidepsin (FK228), have been approved for the treatment of cutaneous T-cell lymphoma [2-4]. In principle, the class- and even isoform-specific HDAC inhibitors are hypothesized to be more beneficial in cancer therapy [5-7].

In 2008, Leusch's group first discovered Largazole from a marine Cyanobacterium of the genus Symploca [8,9]. Largazole shows potent and highly selective inhibitory activities against Class I HDACs and displays superior anticancer properties, attracting great attention among many organic and medicinal chemists [10-14]. Largazole possesses a number of unusual structural 
features, including a 3-hydroxy-7-mercaptohept-4-enoic acid unit and a 16-membered macrocyclic depsipeptide moiety. Interestingly, this side chain unit also appears in several other natural HDAC inhibitors, including Romidepsin (FK228) [15], FR901375 [16,17], and Spiruchostatins (Figure 1) [18]. Psammaplin A, a member of a family of natural products isolated from some marine sponges, contains a similar side chain but with an amide bond instead of an olefin moiety (Figure 1) [19]. All these natural HDAC inhibitors can release a free sulfhydryl residue in vitro and in vivo through either reductive cleavage of the disulfide or hydrolysis of thioester, which is believed to exert inhibitory effects by coordinating with zinc cation of the HDACs (Figure 1) [9-14,19].
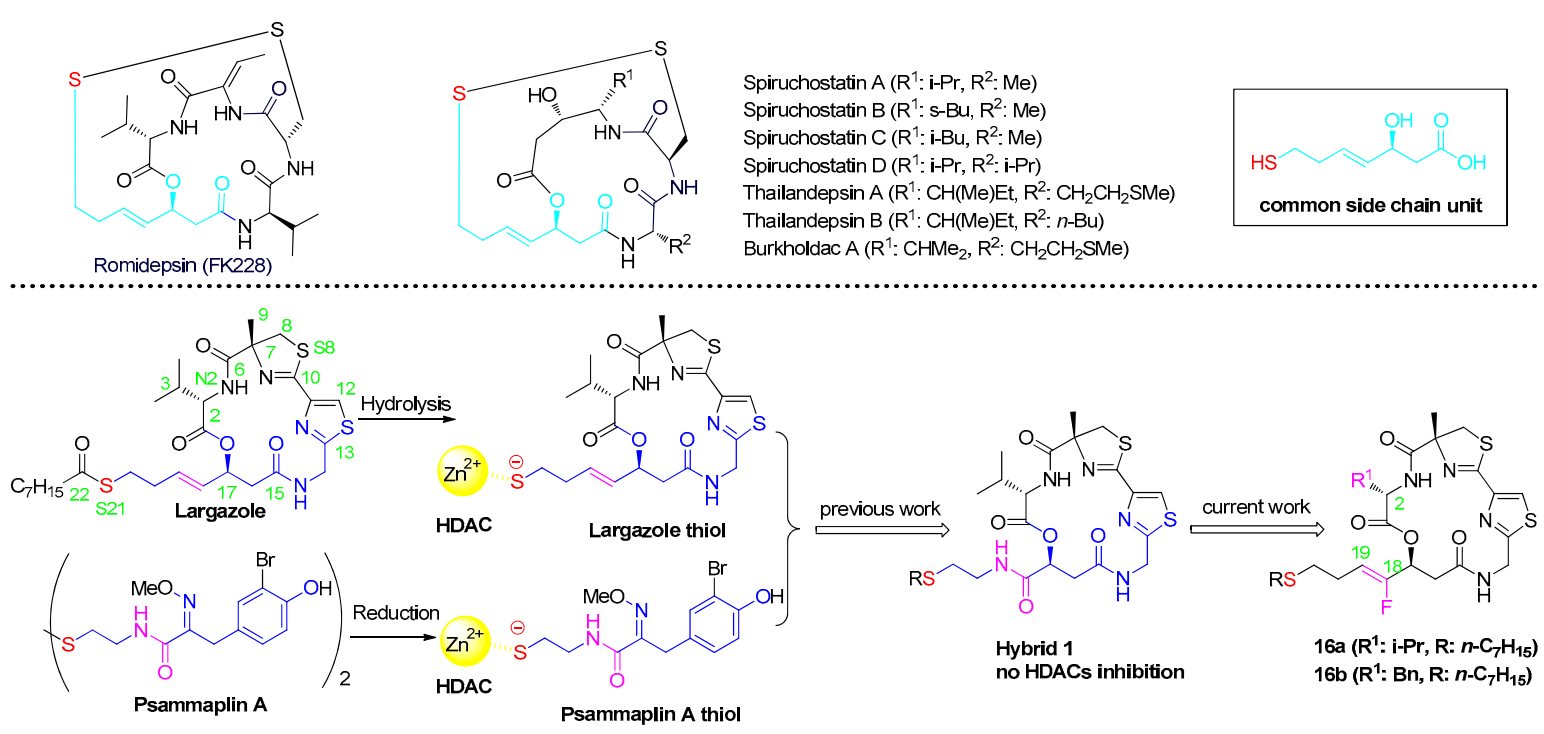

Figure 1. The representative natural histone deacetylases (HDAC) inhibitors and designed analogs of Largazole.

Up to now, great effort has been made to modify the 16-membered macrocyclic depsipeptide moiety of Largazole to search for more selective HDAC inhibitors [20], but modification on the common side chain unit usually leads to the loss of activities through changing the chain length and the stereo-configuration of the double bond and the secondary alcohol, as well as the $\mathrm{Zn}^{2+}$-binding group [21-26], possibly due to limitation of the narrow hydrophobic tunnel of HDACs [27]. Inspired by the structural similarity of the side chain unit of Largazole and Psammaplin, we believed that the unit may play a common role in the inhibition of HDACs. However, our previous work also demonstrated a complete loss of activity when the alkene moiety in Largazole was replaced with the amide moiety [28]. Comparing with trans olefin, trans fluoroolefin is usually viewed as a superior bioisostere of amide bond based on the steric demand, bond length and angle [29], and furthermore, the replacement of the olefin with fluoroolefin has little influence on the rigid conformation of Largazole. Herein, we report our work on synthesis and preliminary biological evaluation of two novel fluoro olefin analogs of Largazole.

\section{Results and Discussion}

\subsection{Chemistry}

The synthesis of two fluoroolefin analogs of Largazole was accomplished according to Scheme 1. The key 4-fluoro analog of chiral 3-hydroxy/amino-7-mercaptohept-4-enoic acid was prepared from acrolein in four steps. Conjugate addition of triphenylmethanethiol (1) to acrolein $\mathbf{2}$ gave $\mathbf{3}$, which was directly used in the following Wittig-Type reaction [30] to give rise to 4 in $97 \%$ yield with Z- and $E$-isomer ratio of $3 / 1$. Although the isomers could be carefully separated by column chromatography, most of the undesired $E$-isomer was found to be isomerized to the Z-isomer during the reduction with DIBALH in anhydrous THF. As a result, a mixture of $Z$ - and $E$-isomer 4 was subjected to the reduction condition, 
giving the fluoro unsaturated aldehyde 5 in $86 \%$ yield. The asymmetric aldol condensation of 5 with acetyl Nagao's auxiliary afforded 4-fluoro derivatives of chiral 3-hydroxy-7-mercaptohept-4-enoic acid (8 and 9) under Xie's conditions $[31,32]$ at a low temperature $\left(-90^{\circ} \mathrm{C}\right)$. The two diastereomers with 2:1 ratio as determined by ${ }^{19} \mathrm{~F}-\mathrm{NMR}$, were readily separated by silica gel column chromatography. The major chiral alcohol $\mathbf{8}$ was assigned to the desired $S$-configuration, while the minor alcohol 9 was designated as the $R$-configuration, according to the known reaction mechanism [32].

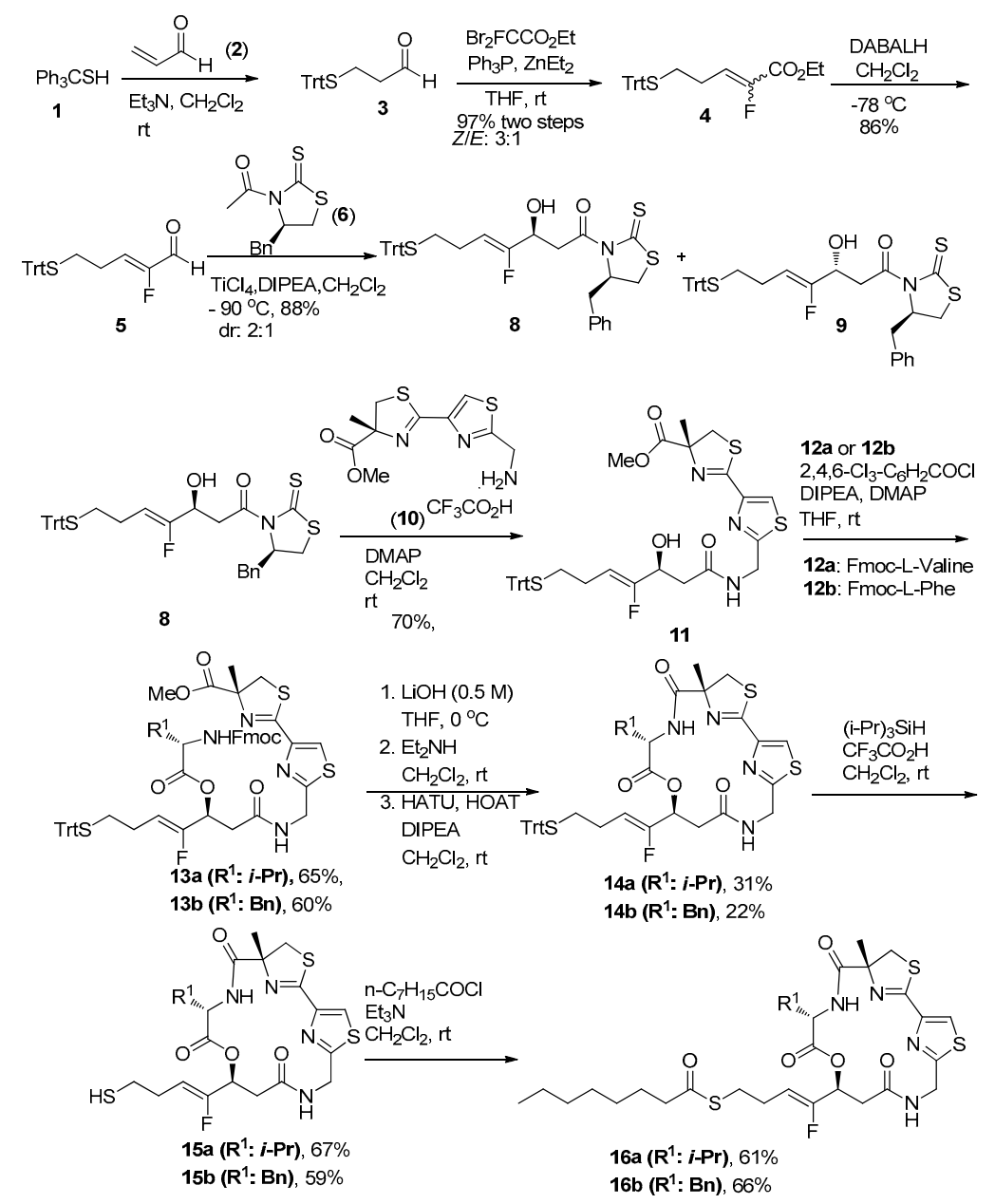

Scheme 1. Synthesis of the analogs of Largazole.

Compound 8 could be directly used for the next aminolysis as Nagao [31] and Xie [32] reported. Aminolysis of 8 with the thiazole-thiazoline fragment (10) [28] under the basic condition provided $\mathbf{1 1}$ in a good yield (70\%). Then, esterification of the secondary alcohol in $\mathbf{1 1}$ with Fmoc-L-Valine (12a) or Fmoc-L-Phenylalanine (12a) pre-activated by $2,4,6-\mathrm{Cl}_{3}-\mathrm{C}_{6} \mathrm{H}_{2} \mathrm{COCl}$ in the presence of DMAP and DIEPA [28], afforded 13a and $\mathbf{1 3 b}$ (yields: $65 \%$ and $60 \%$, respectively). The structures of $13 \mathbf{a}$ and $\mathbf{1 3 b}$ were subsequently confirmed by ${ }^{1} \mathrm{H},{ }^{13} \mathrm{C}, \mathrm{COSY}, \mathrm{HMQC}$ and $\mathrm{HMBC}$ NMR spectra. Careful methyl ester hydrolysis of 13a or $\mathbf{1 3} \mathbf{b}$ in $\mathrm{LiOH}$ solution $\left(\mathrm{THF} / \mathrm{H}_{2} \mathrm{O}\right)$ and removal of Fmoc group with $\mathrm{Et}_{2} \mathrm{NH}$ in $\mathrm{CH}_{2} \mathrm{Cl}_{2}$ resulted in the linear depsipeptide exposed at the $\mathrm{N}$ - and $\mathrm{C}$-terminus, and after examination of several conditions, the system of HATU/HOAT/DIPEA in anhydrous $\mathrm{CH}_{2} \mathrm{Cl}_{2}$ solution (the concentration of cyclization precursor at about $0.001 \mathrm{M}$ ) was used for the macrolactamization, giving 14a and $\mathbf{1 4} \mathbf{b}$ (yields in three steps: $31 \%$ and $22 \%$, respectively). Finally, deprotection of Trt group in 14a and 14b, using (i-Pr) $)_{3} \mathrm{SiH}$ (TIPS) and $\mathrm{CF}_{3} \mathrm{CO}_{2} \mathrm{H}$ in anhydrous $\mathrm{CH}_{2} \mathrm{Cl}_{2}$ solution, proceeded smoothly to afford the free thiol 15a and $\mathbf{1 5 b}$ (yields: $67 \%$ and 59\%, respectively). The subsequent acylation with 
$n-\mathrm{C}_{7} \mathrm{H}_{15} \mathrm{COCl}$ under the standard condition led to the final fluoro analogs $16 \mathbf{a}$ and $\mathbf{1 6 b}$ (yields: $61 \%$ and $66 \%$, respectively).

\subsection{Biology}

In vitro enzymatic assays on Largazole, Largazole free thiol and the related compounds (16a, 15a and 15b) were performed according to the known method [33] with SAHA (Vorinostat) as a reference. The inhibitory potencies against human HDACs (Class I HDACs: 1, 2, 3 and 8; one representative of Class II HDACs: HDAC 6) were evaluated, and the results are shown in Table 1 and Figure 2.

Table 1. In vitro inhibition of human HDACs with Largazole and its analogs.

\begin{tabular}{|c|c|c|c|c|c|c|}
\hline \multirow{2}{*}{ Compound } & \multicolumn{5}{|c|}{$\mathrm{IC}_{50} \pm \mathrm{SD}(\mathrm{nM})^{\mathrm{a}}$} & \multirow{2}{*}{$\begin{array}{l}\text { Selectivity } \\
\text { (HDAC1/6) }\end{array}$} \\
\hline & HDAC1 & HDAC2 & HDAC 3 & HDAC8 & HDAC6 & \\
\hline Largazole & $228 \pm 34$ & $1520 \pm 15$ & $2002 \pm 28$ & $120 \pm 58$ & $>5000$ & $\mathrm{ND}^{\mathrm{b}}$ \\
\hline Largazole thiol & $2.0 \pm 0.0(1.2)^{c}$ & $9.5 \pm 0.2(3.4)^{c}$ & $14.4 \pm 0.2(3.5)^{c}$ & $3.8 \pm 0.2(102){ }^{d}$ & $121 \pm 5.0(49)^{c}$ & $61(40)^{c}$ \\
\hline $16 a$ & $385 \pm 45$ & $1817 \pm 17$ & $2303 \pm 25$ & $255 \pm 92$ & $>5000$ & $\mathrm{ND}^{\mathrm{c}}$ \\
\hline $15 a$ & $4.4 \pm 0.2$ & $21.0 \pm 0.3$ & $39 \pm 2$ & $8.5 \pm 2.5$ & $300 \pm 5$ & 68 \\
\hline $15 b$ & $4.2 \pm 0.3$ & $16.2 \pm 0.4$ & $37.1 \pm 0.7$ & $17.6 \pm 4.1$ & $338 \pm 17$ & 80 \\
\hline SAHA & $19 \pm 4$ & $51 \pm 6$ & $49 \pm 5$ & $328 \pm 138$ & $11 \pm 1$ & 0.24 \\
\hline
\end{tabular}

${ }^{a}$ Compounds were tested in 10-dose $\mathrm{IC}_{50}$ mode in duplicate with threefold serial dilution. ${ }^{\mathrm{b}}$ Not determined. ${ }^{\mathrm{c}}$ The data in the parentheses were those reported by Bradner and Williams in ref. [23]. ${ }^{d}$ The data in the parentheses was reported by Leusch in ref. [34].

As expected, Largazole displayed relatively weaker HDACs inhibitory activities ( $\mathrm{IC}_{50}$ : from 120 to $c a .5000 \mathrm{nM}$ ) in vitro enzymatic assays. In contrast, Largazole thiol, the possibly activated species, displayed potent inhibitory activities on Class I HDACs with $\mathrm{IC}_{50}$ values in the nanomolar range ( $\mathrm{IC}_{50}$ values of $\mathrm{HDAC} 1,2,3$ and 8: 2.0, 9.5, 14.5 and $3.8 \mathrm{nM}$, respectively), and exhibited up to 61-fold selectivity over Class II HDACs exemplified by the $\mathrm{IC}_{50}$ value ratio of HDAC 1 versus HDAC 6 . Most of these results were comparable with those reported [8-11,20,23,34] except HDAC 8 activity ( $3.8 \mathrm{nM}$ verus $102 \mathrm{nM}$ reported by Leusch). Despite that, the above results confirmed that Largazole thiol was a potent and selective Class I HDAC inhibitor, compared to SAHA. 


\section{Largazole}

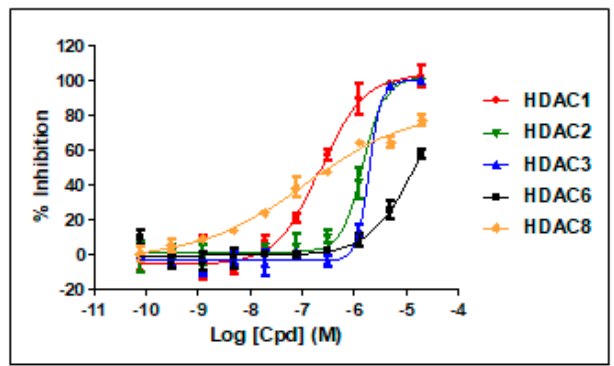

$16 a$

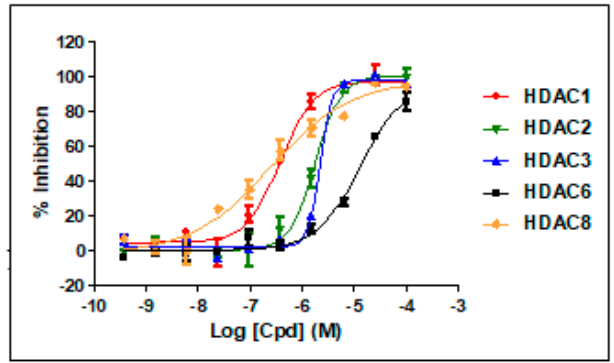

$15 b$

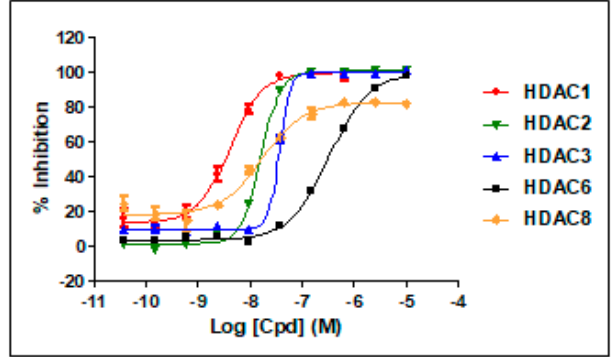

Largazole thiol

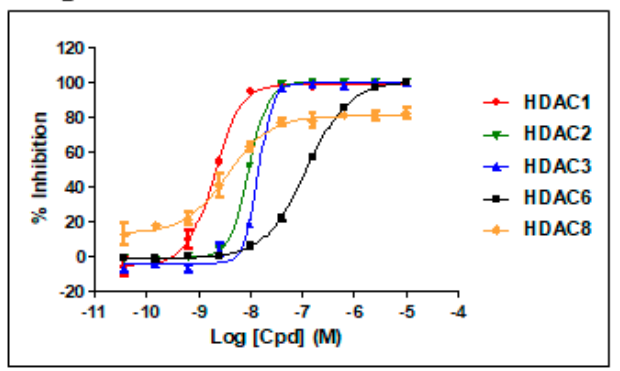

$15 a$

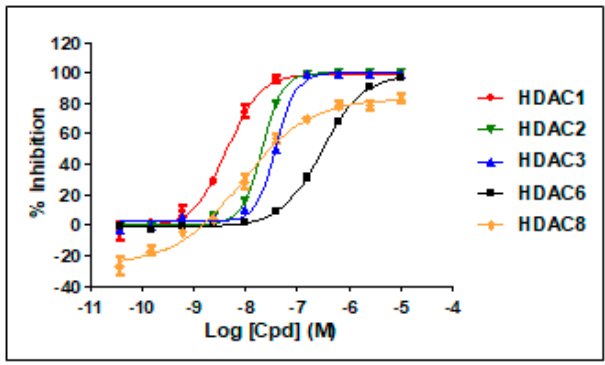

SAHA

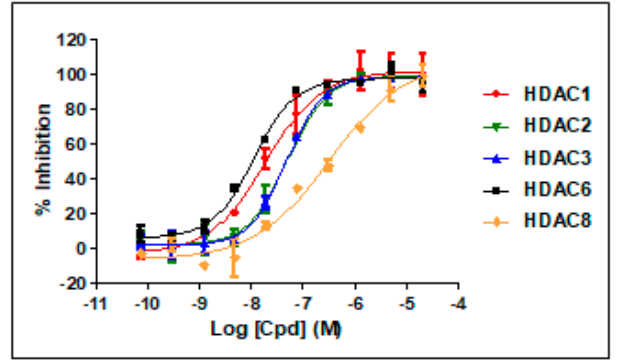

Figure 2. The concentration-response curves of the compounds in the enzymatic assays (HDAC 1, 2, 3, 8 and 6).

Similar to Largazole, the fluoro ester 16a, also displayed relatively weaker HDACs inhibitory activities, and the fluoro thiol 15a exhibited highly potent inhibitory activities on Class I HDACs ( $\mathrm{IC}_{50}$ values of HDAC 1, 2, 3 and 8: 4.4, 21.0, 39.2 and $8.3 \mathrm{nM}$, respectively) and almost the same selectivity over Class II HDACs (about 68-fold selectivity towards HDAC 1 over HDAC 6). These results indicated that the trans alkene moiety in Largazole could be replaced with trans fluoroolefin, which was significantly different from the previous results, because the replacement of trans olefin with an amide bond or aryl ring could lead to a complete loss of activities [14,28]. Furthermore, in contrast to those modifications on the chain length, the stereo-configuration of the double bond or the secondary alcohol of the linker [21-26], our modification was tolerable.

Compared with 15a, the other fluoro thiol (15b), with a benzyl group instead of an $i$-propyl group at C2-position of the macrocycle, also exhibited highly potent and selective inhibitory activities on Class I HDACs ( $\mathrm{IC}_{50}$ values of HDAC 1, 2, 3, 8 and 6: 4.2, 16.2, 37.1, 8.3 and $338 \mathrm{nM}$, respectively). These results indicated that the modification at C2-position could be permitted to some extent with no loss of the activity and selectivity, which was also consistent with the results through the same modification on Laragzole thiol [25].

In the in vitro cell assays, considering the poor cell permeability, Largazole and its analog (16a), instead of their corresponding free thiols, were tested against several cell lines, and the results are shown in Table 2 and Figure 3. Largazole exhibited evident growth inhibition on A549, HCT116, MDA-MB-231, 
and SK-OV-3 cells with $\mathrm{IC}_{50}$ values of $0.46,0.184,1.37$ and $0.034 \mu \mathrm{M}$, respectively. Comparing our data of HCT116 with Luesch's [9], we found our data was about four-fold less potent than the reported data $(0.184 \mu \mathrm{M}$ versus $0.044 \mu \mathrm{M})$, indicating our assays were robust. However, in contrast to nanomolar-range potencies in the enzymatic assays, sub-micromolar-range potencies were observed in the cellular assay. We reasoned that Largazole might extracellularly release the free thiol to some extent in the cellular assays and then result in the diminished potencies due to the poor cell permeability of the free thiol.

Table 2. In vitro growth inhibition of several cells $\left(\mathrm{IC}_{50}, \mu \mathrm{M}\right)$ with Largazole and its analog 16a.

\begin{tabular}{lllll}
\hline \multirow{2}{*}{ Compound } & \multicolumn{4}{c}{ IC $_{\mathbf{5 0}}{ }^{\text {a }} \pm$ SD $(\boldsymbol{\mu M})$} \\
\cline { 2 - 5 } & A549 & HCT116 & MDA-MB-231 & SK-OV-3 \\
\hline Largazole & $0.46 \pm 0.10$ & $0.18 \pm 0.01(0.044)^{\mathrm{b}}$ & $1.37 \pm 0.41$ & $0.03 \pm 0.01$ \\
16a & $0.52 \pm 0.12$ & $0.81 \pm 0.13$ & $3.85 \pm 0.44$ & $0.25 \pm 0.13$ \\
\hline
\end{tabular}

a Compounds were tested in seven-dose $\mathrm{IC}_{50}$ mode in duplicate with four-fold serial dilution. ${ }^{\mathrm{b}}$ The data in the parentheses was reported by Leusch in ref. [9].
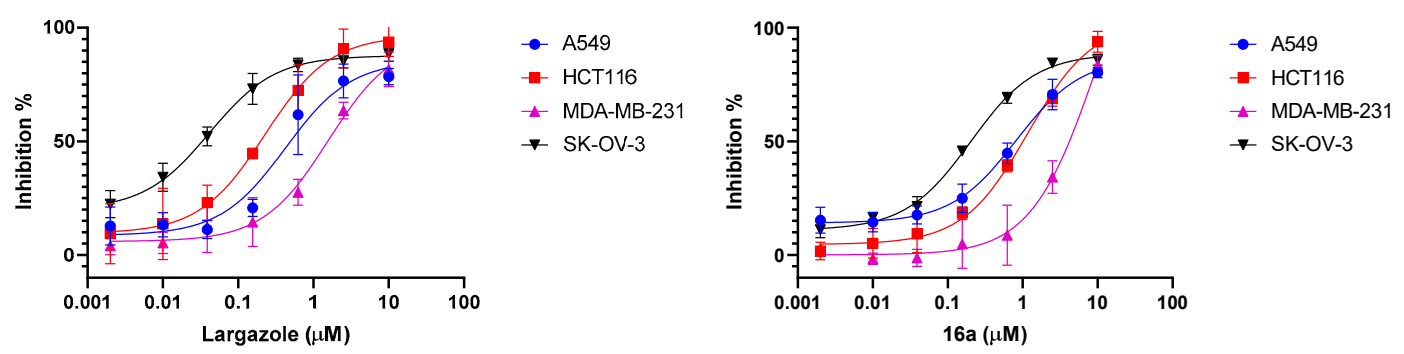

Figure 3. The concentration-response curves of Largazole and 16a in the cellular assays.

As expected, the fluoro olefin analog (16a) gave comparable activities in the A549, HCT116, MDA-MB-231 cellular assay ( IC $_{50}$, A549: $0.52 \mu \mathrm{M}$, HCT116: 0.81 $\mu \mathrm{M}$; MDA-MB-231: $3.85 \mu \mathrm{M}$ ) except SK-OV-3 $\left(\mathrm{IC}_{50}, 0.25 \mu \mathrm{M}\right)$. We reasoned that there may be more extracellular release of its free thiol in the case of SK-OV-3. Taken together, based on both enzymatic and cellular assays, we demonstrated that fluorine could be introduced into the alkene moiety of the Largazole with little sacrifice of the activities and selectivity. The kind of modification might be feasible for this family of the natural products (Figure 1) sharing the common side chain, and further study is under way.

\section{Materials and Methods}

\subsection{Chemistry}

The chemicals and reagents were purchased from Acros, Alfa Aesar, and National Chemical Reagent Group Co. Ltd., Shanghai, China, and used without further purification. Anhydrous solvents (THF, $\mathrm{MeOH}, \mathrm{DMF}, \mathrm{CH}_{2} \mathrm{Cl}_{2}$, and $\mathrm{CH}_{3} \mathrm{CN}$ ) used in the reactions were dried and freshly distilled before use. All the reactions were carried out under Ar atmosphere, otherwise stated else. The progress of the reactions was monitored by TLC (silica-coated glass plates) and visualized under UV light, and by using iodine or phosphomolybdic acid. Melting points were measured on an SGW X-4 microscopy melting point apparatus without correction. ${ }^{1} \mathrm{H}-\mathrm{NMR}$ and ${ }^{13} \mathrm{C}-\mathrm{NMR}$ spectra were recorded either on a $400 \mathrm{MHz}$ Varian Instrument at $25^{\circ} \mathrm{C}$ or $600 \mathrm{MHz}$ Bruker Instrument at $25^{\circ} \mathrm{C}$, using TMS as an internal standard, respectively. Multiplicity is tabulated as s for singlet, $\mathrm{d}$ for doublet, $\mathrm{dd}$ for doublet of doublet, $\mathrm{t}$ for triplet, and $\mathrm{m}$ for multiplet. The original spectra of the relative compounds could be found in Supplementary Materials. HRMS spectra were recorded on Finnigan-Mat-95 mass spectrometer, equipped with an ESI source. Experimental procedures for the preparation of compound 10 and Largazole are available in the reported literature [28]. 


\section{3-(Tritylthio)propanal (3)}

To a solution of triphenylmethyl mercaptan ( $1.38 \mathrm{~g}, 5.0 \mathrm{mmol}$, 1.0 equiv.) in $\mathrm{CH}_{2} \mathrm{Cl}_{2}$ (DCM, $30 \mathrm{~mL}$ ) acrolein $(0.393 \mathrm{~g}, 7.0 \mathrm{mmol}, 1.4$ equiv. $)$ and triethylamine $(0.98 \mathrm{~mL}, 7.0 \mathrm{mmol}, 1.4$ equiv.) was added, and the resulting mixture was stirred at room temperature for $1 \mathrm{~h}$. Concentration in vacuo left aldehyde 3 as a white foamy solid. $R_{\mathrm{f}}=0.13$ [petroleum ether (PE)/ethyl acetate (EA) 40/1], ${ }^{1} \mathrm{H}-\mathrm{NMR}(400 \mathrm{MHz}$, $\left.\mathrm{CDCl}_{3}\right): \delta 9.56(\mathrm{brs}, 1 \mathrm{H}), 7.23-7.43(\mathrm{~m}, 15 \mathrm{H}), 2.47(\mathrm{t}, J=7.0 \mathrm{~Hz}, 2 \mathrm{H}), 2.37(\mathrm{t}, J=6.7 \mathrm{~Hz}, 2 \mathrm{H})$.

\section{Ethyl 2-fluoro-5-(tritylthio)pent-2-enoate (4)}

To an anhydrous THF solution $(30 \mathrm{~mL})$ of $\mathrm{PPh}_{3}(3.15 \mathrm{~g}, 12.0 \mathrm{mmol}, 4.0$ equiv) and ethyl bromodifluoroacetate $\left(0.83 \mathrm{~mL}, 6.0 \mathrm{mmol}, 2.0\right.$ equiv), $1.0 \mathrm{M} \mathrm{Et}_{2} \mathrm{Zn}$ in hexane (12 mL, $12.0 \mathrm{mmol}$, 4.0 equiv) was rapidly added under argon. The mixture was stirred for $10 \mathrm{~min}$ (until the internal temperature returned to $\mathrm{rt})$, then the aldehyde $3(0.997 \mathrm{~g}, 3.0 \mathrm{mmol})$ was rapidly added. The mixture was stirred overnight. The resulting solution was then quenched with $\mathrm{EtOH}(15 \mathrm{~mL})$, stirred for $15 \mathrm{~min}$, and concentrated under reduced pressure. The residue was taken up in $\mathrm{Et}_{2} \mathrm{O}(100 \mathrm{~mL})$ and filtered through Celite and then it was chromatographed (silica gel, PE/EA 40/1) to afford the a-fluoroacrylate 4, with E-isomer $(0.325 \mathrm{~g}, 26 \%)$ and Z-isomer $(0.730 \mathrm{~g}, 58 \%)$, respectively, or afford 4 with a mixture of them (Z/E 3/1, determined by ${ }^{19} \mathrm{~F}$ NMR) in $97 \%$ yield.

For Z-4: $R_{\mathrm{f}}=0.35(\mathrm{PE} / \mathrm{EA} 40 / 1) .{ }^{1} \mathrm{H}-\mathrm{NMR}\left(400 \mathrm{MHz}, \mathrm{CDCl}_{3}\right): \delta 7.40(\mathrm{~m}, 6 \mathrm{H}), 7.25(\mathrm{~m}, 6 \mathrm{H})$, $7.18(\mathrm{~m}, 3 \mathrm{H}), 5.75(\mathrm{dt}, J=20.9,7.9 \mathrm{~Hz}, 1 \mathrm{H}), 4.23(\mathrm{q}, J=7.1 \mathrm{~Hz}, 2 \mathrm{H}), 2.56(\mathrm{~m}, 2 \mathrm{H}), 2.26(\mathrm{t}, J=7.2 \mathrm{~Hz}$, $2 \mathrm{H}), 1.29(\mathrm{t}, J=7.1 \mathrm{~Hz}, 3 \mathrm{H}) \cdot{ }^{13} \mathrm{C}-\mathrm{NMR}\left(150 \mathrm{MHz}, \mathrm{CDCl}_{3}\right): \delta 160.58\left(\mathrm{~d},{ }^{2} J_{\mathrm{C}-\mathrm{F}}=34.5 \mathrm{~Hz}\right), 147.91(\mathrm{~d}$, $\left.{ }^{1} J_{\mathrm{C}-\mathrm{F}}=252 \mathrm{~Hz}\right), 144.65,129.48,127.81,126.60,121.24\left(\mathrm{~d},{ }^{2} J_{\mathrm{C}-\mathrm{F}}=19.6 \mathrm{~Hz}\right), 66.71,61.28,31.30,24.55(\mathrm{~d}$, $\left.{ }^{3} J_{\mathrm{C}-\mathrm{F}}=5.1 \mathrm{~Hz}\right), 14.00 .{ }^{19} \mathrm{~F}-\mathrm{NMR}\left(376 \mathrm{MHz}, \mathrm{CDCl}_{3}\right): \delta-121.29(\mathrm{~d}, J=22.6 \mathrm{~Hz})$. ESI-MS $(\mathrm{m} / \mathrm{z}): 443.6$ $[\mathrm{M}+\mathrm{Na}]^{+}$. HRMS-ESI $(\mathrm{m} / \mathrm{z})$ : $[\mathrm{M}+\mathrm{Na}]^{+}$calcd. for $\mathrm{C}_{26} \mathrm{H}_{25} \mathrm{FO}_{2} \mathrm{SNa}$ : 443.1452, found: 443.1452.

For $E-4: R_{\mathrm{f}}=0.27(\mathrm{PE} / \mathrm{EA} 40 / 1) .{ }^{1} \mathrm{H}-\mathrm{NMR}\left(400 \mathrm{MHz}, \mathrm{CDCl}_{3}\right): \delta 7.41(\mathrm{~m}, 6 \mathrm{H}), 7.28(\mathrm{~m}, 6 \mathrm{H}), 7.22(\mathrm{~m}$, $3 \mathrm{H}), 5.97(\mathrm{dt}, J=32.8,7.2 \mathrm{~Hz}, 1 \mathrm{H}), 4.25(\mathrm{q}, J=7.1 \mathrm{~Hz}, 2 \mathrm{H}), 2.25(\mathrm{~m}, 4 \mathrm{H}), 1.31(\mathrm{t}, J=7.1 \mathrm{~Hz}, 3 \mathrm{H}) .{ }^{13} \mathrm{C}-\mathrm{NMR}$ $\left(150 \mathrm{MHz}, \mathrm{CDCl}_{3}\right): \delta 155.83\left(\mathrm{~d},{ }^{2} J_{\mathrm{C}-\mathrm{F}}=34.5 \mathrm{~Hz}\right), 143.62\left(\mathrm{~d},{ }^{1} J_{\mathrm{C}-\mathrm{F}}=256.5 \mathrm{~Hz}\right), 139.93,124.82,123.19$, $121.99,113.57\left(\mathrm{~d},{ }^{2} J_{\mathrm{C}-\mathrm{F}}=11.4 \mathrm{~Hz}\right), 62.15,56.85,25.79,18.90,9.39 .{ }^{19} \mathrm{~F}-\mathrm{NMR}\left(376 \mathrm{MHz}, \mathrm{CDCl}_{3}\right): \delta-128.95$ $(\mathrm{d}, J=32.8 \mathrm{~Hz})$. ESI-MS $(\mathrm{m} / \mathrm{z}): 443.6[\mathrm{M}+\mathrm{Na}]^{+}$. HRMS-ESI $(\mathrm{m} / \mathrm{z}):[\mathrm{M}+\mathrm{Na}]^{+}$calcd. for $\mathrm{C}_{26} \mathrm{H}_{25} \mathrm{FO}_{2} \mathrm{SNa}$ : 443.1452, found: 443.1454 .

\section{(Z)-2-Fluoro-5-(tritylthio)pent-2-enal (5)}

To an anhydrous toluene solution $(100 \mathrm{~mL})$ of a mixture of Z-4 and $E-4$ prepared above (4.03 $\mathrm{g}$, $9.58 \mathrm{mmol}) 1.5 \mathrm{M}$ DIBALH in toluene $(22.4 \mathrm{~mL}, 33.5 \mathrm{mmol})$ was added dropwise under argon at $-78^{\circ} \mathrm{C}$ over $0.5 \mathrm{~h}$. The mixture was stirred at $-78^{\circ} \mathrm{C}$ for $1 \mathrm{~h}$, and the resulting solution was then quenched with $\mathrm{MeOH}(50 \mathrm{~mL})$, and warmed to rt. After addition of the saturated aqueous solution of Rochelle salt, the mixture was stirred for overnight, and then the organic phase was separated. The aqueous phase was extracted with EA $(100 \mathrm{~mL} \times 2)$, and the combined organic extracts were dried, filtered, and concentrated in vacuo, and then it was chromatographed (silica gel, PE/DCM/EA 35/5/1) to afford the aldehyde 5 as a white foamy solid $(3.10 \mathrm{~g}, 86 \%) . R_{\mathrm{f}}=0.35(\mathrm{PE} / \mathrm{DCM} / \mathrm{EA} 35 / 5 / 1) .{ }^{1} \mathrm{H}-\mathrm{NMR}(400 \mathrm{MHz}$, $\left.\mathrm{CDCl}_{3}\right): \delta 9.13(\mathrm{~d}, J=18.2 \mathrm{~Hz}, 1 \mathrm{H}), 7.43(\mathrm{~m}, 6 \mathrm{H}), 7.27(\mathrm{~m}, 9 \mathrm{H}), 5.75(\mathrm{dt}, J=32.1,7.2 \mathrm{~Hz}, 1 \mathrm{H}), 2.35(\mathrm{~m}, 4 \mathrm{H})$. ${ }^{13} \mathrm{C}-\mathrm{NMR}\left(100 \mathrm{MHz}, \mathrm{CDCl}_{3}\right): \delta 183.49\left(\mathrm{~d},{ }^{2} J_{\mathrm{C}-\mathrm{F}}=24.9 \mathrm{~Hz}\right), 156.48\left(\mathrm{~d},{ }^{1} J_{\mathrm{C}-\mathrm{F}}=261 \mathrm{~Hz}\right), 146.88,144.53$, $129.54,128.71\left(\mathrm{~d},{ }^{2} J_{\mathrm{C}-\mathrm{F}}=10.2 \mathrm{~Hz}\right), 127.99,127.92,127.29,126.86,67.09,30.22,24.01 .{ }^{19} \mathrm{~F}-\mathrm{NMR}(376 \mathrm{MHz}$, $\left.\mathrm{CDCl}_{3}\right): \delta-132.15(\mathrm{dd}, J=32.1,18.2 \mathrm{~Hz})$. ESI-MS $(\mathrm{m} / \mathrm{z}): 399.6[\mathrm{M}+\mathrm{Na}]^{+}$. HRMS-ESI $(\mathrm{m} / \mathrm{z}):[\mathrm{M}+\mathrm{Na}]^{+}$ calcd. for $\mathrm{C}_{24} \mathrm{H}_{21}$ FOSNa: 399.1189, found: 399.1192 .

(S/R,Z)-1-((R)-4-Benzyl-2-thioxothiazolidin-3-yl)-4-fluoro-3-hydroxy-7-(tritylthio)hept-4-en-1-one (8/9)

$6(1.12 \mathrm{~g}, 4.46 \mathrm{mmol})$ was dissolved in dry DCM $(50 \mathrm{~mL})$ and cooled to $0{ }^{\circ} \mathrm{C}$. $\mathrm{TiCl}_{4}(0.82 \mathrm{~mL}$, $7.43 \mathrm{mmol}$ ) was added dropwise. After stirring for $30 \mathrm{~min}$, the resulting yellow suspension was cooled to $-40^{\circ} \mathrm{C}$. $i$ - $\operatorname{Pr}_{2} \mathrm{NEt}(1.32 \mathrm{~mL}, 7.97 \mathrm{mmol})$ was then added dropwise, and the reaction mixture was stirred for $2 \mathrm{~h}$ at this temperature. The resulting solution was then cooled to $-90^{\circ} \mathrm{C} .5(1.44 \mathrm{~g}, 3.71 \mathrm{mmol})$ 
was dissolved in dry DCM $(20 \mathrm{~mL})$ and added dropwise to the reaction mixture. The reaction mixture was stirred at $-90^{\circ} \mathrm{C}$ for $3 \mathrm{~h}$ and quenched by the addition of a saturated aqueous solution of $\mathrm{NH}_{4} \mathrm{Cl}$. The reaction mixture was then allowed to warm to room temperature and extracted three times with DCM $(20 \mathrm{~mL} \times 3)$. The combined organic layers were washed with brine, dried over $\mathrm{Na}_{2} \mathrm{SO}_{4}$, filtered, and the solvent evaporated under reduced pressure. The resulting crude was purified by flash chromatography on silica gel, eluting with PE/EA (8/1) to afford $8(1.33 \mathrm{~g}, 59 \%)$ and $\mathbf{9}(0.656 \mathrm{~g}, 29 \%)$ as yellow oils, respectively.

For 8: $R_{\mathrm{f}}=0.19(\mathrm{PE} / \mathrm{EA} \mathrm{4/1}) .[\alpha]^{20}{ }_{\mathrm{D}}:-78.0\left(\mathrm{c} 3.7, \mathrm{CHCl}_{3}\right) .{ }^{1} \mathrm{H}-\mathrm{NMR}\left(400 \mathrm{MHz}, \mathrm{CDCl}_{3}\right): \delta 7.29$ $(\mathrm{m}, 20 \mathrm{H}), 5.33(\mathrm{~m}, 1 \mathrm{H}), 4.86(\mathrm{dd}, J=36.8,7.1 \mathrm{~Hz}, 1 \mathrm{H}), 4.63(\mathrm{brs}, 1 \mathrm{H}), 3.67(\mathrm{~m}, 1 \mathrm{H}), 3.47(\mathrm{dd}, J=17.9,8.8 \mathrm{~Hz}$, $1 \mathrm{H}), 3.36(\mathrm{dd}, J=11.2,7.2 \mathrm{~Hz}, 1 \mathrm{H}), 3.21(\mathrm{~m}, 1 \mathrm{H}), 3.03(\mathrm{~m}, 1 \mathrm{H}), 2.95(\mathrm{~d}, J=4.1 \mathrm{~Hz}, 1 \mathrm{H}), 2.87(\mathrm{~d}, J=11.6 \mathrm{~Hz}$, 1H), $2.19(\mathrm{~m}, 4 \mathrm{H}) .{ }^{13} \mathrm{C}-\mathrm{NMR}\left(150 \mathrm{MHz}, \mathrm{CDCl}_{3}\right): \delta 201.27,172.02,158.60\left(\mathrm{~d},{ }^{1} \mathrm{~J}_{\mathrm{C}-\mathrm{F}}=257.2 \mathrm{~Hz}\right), 144.87$, 136.32, 129.60, 129.45, 128.97, 127.88, 127.34, 126.63, $104.96\left(\mathrm{~d},{ }^{2} \mathrm{~J}_{\mathrm{C}-\mathrm{F}}=12.9 \mathrm{~Hz}\right), 68.32,66.63,42.81$, 36.79, 32.18, 31.52, 22.72. ${ }^{19} \mathrm{~F}-\mathrm{NMR}\left(376 \mathrm{MHz}, \mathrm{CDCl}_{3}\right): \delta-129.15$ (dd, $\left.J=32.1,18.2 \mathrm{~Hz}\right)$. ESI-MS $(\mathrm{m} / \mathrm{z})$ : $650.4[\mathrm{M}+\mathrm{Na}]^{+}$. HRMS-ESI $(\mathrm{m} / \mathrm{z})$ : $[\mathrm{M}+\mathrm{Na}]^{+}$calcd. for $\mathrm{C}_{36} \mathrm{H}_{34} \mathrm{FNO}_{2} \mathrm{~S}_{3} \mathrm{Na}: 650.1628$, found: 650.1621 .

For 9: $R_{\mathrm{f}}=0.30(\mathrm{PE} / \mathrm{EA} 4 / 1) .[\alpha]^{20}{ }_{\mathrm{D}}:-65.4\left(c\right.$ 0.30, $\left.\mathrm{CHCl}_{3}\right) .{ }^{1} \mathrm{H}-\mathrm{NMR}\left(400 \mathrm{MHz}, \mathrm{CDCl}_{3}\right): \delta 7.30$ $(\mathrm{m}, 20 \mathrm{H}), 5.37(\mathrm{~m}, 1 \mathrm{H}), 4.85(\mathrm{dt}, J=37.2,7.0 \mathrm{~Hz}, 1 \mathrm{H}), 4.56(\mathrm{brs}, 1 \mathrm{H}), 3.75(\mathrm{dd}, J=17.5,9.2 \mathrm{~Hz}, 1 \mathrm{H})$, $3.41(\mathrm{~m}, 2 \mathrm{H}), 3.21(\mathrm{~m}, 2 \mathrm{H}), 3.03(\mathrm{dd}, J=13.2,10.4 \mathrm{~Hz}, 1 \mathrm{H}), 2.89(\mathrm{~d}, J=11.6 \mathrm{~Hz}, 1 \mathrm{H}), 2.19(\mathrm{~m}, 4 \mathrm{H})$. ${ }^{13} \mathrm{C}-\mathrm{NMR}\left(150 \mathrm{MHz}, \mathrm{CDCl}_{3}\right): \delta 201.27,172.02,158.60\left(\mathrm{~d},{ }^{1} J_{\mathrm{C}-\mathrm{F}}=257.2 \mathrm{~Hz}\right), 144.87,136.32,129.60,129.45$, $128.97,127.88,127.34,126.63,104.96\left(\mathrm{~d},{ }^{2} J_{\mathrm{C}-\mathrm{F}}=12.9 \mathrm{~Hz}\right), 68.32,66.63,42.81,36.79,32.18,31.52,22.72$. ESI-MS $(\mathrm{m} / \mathrm{z}): 650.4[\mathrm{M}+\mathrm{Na}]^{+}$. HRMS-ESI $(\mathrm{m} / \mathrm{z}):[\mathrm{M}+\mathrm{Na}]^{+}$calcd. for $\mathrm{C}_{36} \mathrm{H}_{34} \mathrm{FNO}_{2} \mathrm{~S}_{3} \mathrm{Na}: 650.1628$, found: 650.1621 .

(R)-Methyl 2'-((S/R,Z)-4-fluoro-3-hydroxy-7-(tritylthio)hept-4-enamido)methyl)-4-methyl-4,5-dihydro-[2, 4'-bithiazole]-4-carboxylate (31S/31R) (11)

To a stirring solution of $\mathbf{1 0}(0.459 \mathrm{~g}, 1.28 \mathrm{mmol})$ and DMAP $(0.408 \mathrm{~g}, 3.34 \mathrm{mmol})$ in anhydrous DCM $(20 \mathrm{~mL})$ a solution of $8(0.820 \mathrm{~g}, 1.28 \mathrm{mmol})$ in DCM $(20 \mathrm{~mL})$ was added dropwise at $\mathrm{rt}$, and the resultant solution was stirred for another $2 \mathrm{~h}$. The solution was then quenched with $\mathrm{NH}_{4} \mathrm{Cl}$ saturated solution $(20 \mathrm{~mL})$ and separated, and the aqueous phase was extracted with $\mathrm{DCM}(30 \mathrm{~mL} \times 3)$. The combined organic phase was washed successively with $\mathrm{H}_{2} \mathrm{O}$, brine, dried with $\mathrm{Na}_{2} \mathrm{SO}_{4}$ and filtered. After removal of the solvent, the residue was purified by flash chromatography on silica gel with DCM/EA (2/1) to yield $11(0.600 \mathrm{~g}, 70 \%)$ as a foamy solid.

$R_{\mathrm{f}}=0.26(\mathrm{PE} / \mathrm{EA} 1 / 1) .[\alpha]^{20}{ }_{\mathrm{D}}:-32.2\left(c\right.$ 3.6, $\left.\mathrm{CHCl}_{3}\right) .{ }^{1} \mathrm{H}-\mathrm{NMR}\left(400 \mathrm{MHz}, \mathrm{CDCl}_{3}\right): \delta 7.89(\mathrm{~s}, 1 \mathrm{H})$, $4.79(\mathrm{~m}, 2 \mathrm{H}), 4.68(\mathrm{~m}, 2 \mathrm{H}), 4.49(\mathrm{brs}, 1 \mathrm{H}), 3.87(\mathrm{~d}, J=11.4 \mathrm{~Hz}, 1 \mathrm{H}), 3.79(\mathrm{~s}, 3 \mathrm{H}), 3.27(\mathrm{~d}, J=11.4 \mathrm{~Hz}, 1 \mathrm{H})$, $2.56(\mathrm{~m}, 2 \mathrm{H}), 2.15(\mathrm{~m}, 5 \mathrm{H}), 1.63(\mathrm{~s}, 3 \mathrm{H}) .{ }^{13} \mathrm{C}-\mathrm{NMR}\left(100 \mathrm{MHz}, \mathrm{CDCl}_{3}\right): \delta 173.62,171.49,167.63,162.78$, $158.92\left(\mathrm{~d},{ }^{1} J_{\mathrm{C}-\mathrm{F}}=257.4 \mathrm{~Hz}\right), 148.20,144.83,129.58,127.91,126.67,122.56,104.67\left(\mathrm{~d},{ }^{2} J_{\mathrm{C}-\mathrm{F}}=12.3 \mathrm{~Hz}\right), 84.49$, $66.97\left(\mathrm{~d},{ }^{2} J_{\mathrm{C}-\mathrm{F}}=33 \mathrm{~Hz}\right), 66.62,53.01,41.54,40.80,39.72,31.49,24.02,22.70\left(\mathrm{~d},{ }^{3} \mathrm{~J}_{\mathrm{C}-\mathrm{F}}=3.5 \mathrm{~Hz}\right) .{ }^{19} \mathrm{~F}-\mathrm{NMR}$ $\left(376 \mathrm{MHz}, \mathrm{CDCl}_{3}\right): \delta-124.95(\mathrm{dd}, J=36.2,20.3 \mathrm{~Hz})$. ESI-MS $(\mathrm{m} / \mathrm{z}): 712.4[\mathrm{M}+\mathrm{Na}]^{+}$. HRMS-ESI $(\mathrm{m} / \mathrm{z})$ : $[\mathrm{M}+\mathrm{Na}]^{+}$calcd. for $\mathrm{C}_{36} \mathrm{H}_{36} \mathrm{FN}_{3} \mathrm{O}_{4} \mathrm{~S}_{3} \mathrm{Na}$ : 712.1744, found: 712.1748 .

(R)-Methyl 2'-((5S/R,8S)-1-(9H-fluoren-9-yl)-8-((Z)-1-fluoro-4-(tritylthio)but-1-en-1-yl)-5-isopropyl-3,6, 10-trioxo-2,7-dioxa-4,11-diazadodecan-12-yl)-4-methyl-4,5-dihydro-[2,4'-bithiazole]-4-carboxylate (13a)

To a solution of Fmoc-Val-OH $(0.165 \mathrm{~g}, 0.49 \mathrm{mmol})$ and DMAP $(0.005 \mathrm{~g}, 0.041 \mathrm{mmol})$ in DCM (15 mL) 2,4,6-trichlorobenzoyl chloride $(0.089 \mathrm{~mL}, 0.568 \mathrm{mmol})$ was added at $0{ }^{\circ} \mathrm{C}$, and then the solution continued to stirred for $1 \mathrm{~h}$. Then. a solution of 11 and DIPEA $(0.11 \mathrm{~mL}, 0.65 \mathrm{mmol})$ in DCM $(10 \mathrm{~mL})$ was added to the stirring mixture. The reaction was allowed to warm to $\mathrm{rt}$ and stirred for $1 \mathrm{~h}$. This solution was quenched with a $\mathrm{NH}_{4} \mathrm{Cl}$ aqueous solution and separated. The aqueous phase was extracted with $\mathrm{DCM}(30 \mathrm{~mL} \times 3)$ and the combined organic phase was washed successively with $\mathrm{H}_{2} \mathrm{O}$, brine, dried with $\mathrm{Na}_{2} \mathrm{SO}_{4}$ and filtered. After the removal of the solvent, the resulting crude was purified by flash chromatography on silica gel, eluting with PE/EA (5/4) to afford 13a $(0.266 \mathrm{~g}, 65 \%)$ as a white foamy solid. $R_{\mathrm{f}}=0.26(\mathrm{PE} / \mathrm{EA} 1 / 1) .[\alpha]^{20} \mathrm{D}:-16.4\left(c 0.34, \mathrm{CHCl}_{3}\right) .{ }^{1} \mathrm{H}-\mathrm{NMR}(600 \mathrm{MHz}$, 
$\left.\mathrm{CDCl}_{3}\right): \delta 7.89(\mathrm{~s}, 1 \mathrm{H}), 7.75(\mathrm{~d}, J=7.2 \mathrm{~Hz}, 2 \mathrm{H}), 7.57(\mathrm{~d}, J=3.6 \mathrm{~Hz}, 2 \mathrm{H}), 7.38(\mathrm{~m}, 8 \mathrm{H}), 7.34-7.24(\mathrm{~m}, 8 \mathrm{H})$, $7.20(\mathrm{t}, J=7.1 \mathrm{~Hz}, 3 \mathrm{H}), 6.64(\mathrm{brs}, 1 \mathrm{H}), 5.67-5.79(\mathrm{~m}, 1 \mathrm{H}), 5.25(\mathrm{brs}, 1 \mathrm{H}), 4.92(\mathrm{dt}, J=35.9,7.0 \mathrm{~Hz}, 1 \mathrm{H})$, $4.68(\mathrm{~m}, 2 \mathrm{H}), 4.37(\mathrm{~m}, 2 \mathrm{H}), 4.20(\mathrm{t}, J=6.9 \mathrm{~Hz}, 1 \mathrm{H}), 4.16(\mathrm{dd}, J=7.6,5.8 \mathrm{~Hz}, 1 \mathrm{H}), 3.85(\mathrm{~d}, J=11.3 \mathrm{~Hz}, 1 \mathrm{H})$, $3.78(\mathrm{~s}, 3 \mathrm{H}), 3.24(\mathrm{~d}, J=11.3 \mathrm{~Hz}, 1 \mathrm{H}), 2.70(\mathrm{~m}, 2 \mathrm{H}), 2.01-2.24(\mathrm{~m}, 5 \mathrm{H}), 1.63(\mathrm{~s}, 3 \mathrm{H}), 0.88(\mathrm{t}, J=6.5 \mathrm{~Hz}$, $3 \mathrm{H}), 0.83(\mathrm{~d}, J=6.6 \mathrm{~Hz}, 3 \mathrm{H}) .{ }^{13} \mathrm{C}-\mathrm{NMR}\left(150 \mathrm{MHz}, \mathrm{CDCl}_{3}\right): \delta 173.62,170.92,168.24,167.81,162.77$, $156.29,153.75\left(\mathrm{~d},{ }^{1} J_{\mathrm{C}-\mathrm{F}}=257.4 \mathrm{~Hz}\right), 148.35,144.78,143.79\left(\mathrm{~d}, J_{\mathrm{C}-\mathrm{F}}=19.3 \mathrm{~Hz}\right), 141.33,129.58,127.91$, $127.82\left(\mathrm{~d}, J_{\mathrm{C}-\mathrm{F}}=24.5 \mathrm{~Hz}\right), 127.12,126.68,125.08,122.33,120.00,109.63\left(\mathrm{~d},{ }^{2} J_{\mathrm{C}-\mathrm{F}}=12.0 \mathrm{~Hz}\right), 84.56,69.62(\mathrm{~d}$, $\left.{ }^{3} J_{\mathrm{C}-\mathrm{F}}=28.5 \mathrm{~Hz}\right), 67.08,66.71,59.17,52.91,47.19,41.53,41.09,38.02,31.59,31.10(\mathrm{~d}, J=10.2 \mathrm{~Hz}), 23.98$, 22.79, 22.66, 18.81, 17.71. ${ }^{19} \mathrm{~F}$ NMR $\left(376 \mathrm{MHz}, \mathrm{CDCl}_{3}\right): \delta-125.77(\mathrm{dd}, J=35.4,21.1 \mathrm{~Hz})$. ESI-MS $(\mathrm{m} / \mathrm{z})$ : 1011.2 [M + H] $]^{+}$. HRMS-ESI ( $\left./ z / z\right):[\mathrm{M}+\mathrm{Na}]^{+}$calcd. for $\mathrm{C}_{56} \mathrm{H}_{55} \mathrm{FN}_{4} \mathrm{O}_{7} \mathrm{~S}_{3} \mathrm{Na}$ : 1033.3109, found: 1033.3102 .

For 13b: 60\%, $R_{\mathrm{f}}=0.26(\mathrm{PE} / \mathrm{EA} 1 / 1) .[\alpha]^{20}{ }_{\mathrm{D}}:-4.7\left(\mathrm{c}=0.097, \mathrm{CHCl}_{3}\right) .{ }^{1} \mathrm{H}-\mathrm{NMR}\left(600 \mathrm{MHz}, \mathrm{CDCl}_{3}\right)$ $\delta 7.89(\mathrm{~s}, 1 \mathrm{H}), 7.76(\mathrm{~d}, J=7.5 \mathrm{~Hz}, 2 \mathrm{H}), 7.53(\mathrm{t}, J=7.2 \mathrm{~Hz}, 2 \mathrm{H}), 7.39(\mathrm{~d}, J=7.4 \mathrm{~Hz}, 8 \mathrm{H}), 7.33-7.25(\mathrm{~m}, 9 \mathrm{H})$, $7.19(\mathrm{dd}, J=16.7,7.7 \mathrm{~Hz}, 6 \mathrm{H}), 7.04(\mathrm{~d}, J=6.9 \mathrm{~Hz}, 2 \mathrm{H}), 6.60(\mathrm{~s}, 1 \mathrm{H}), 5.77-5.57(\mathrm{~m}, 1 \mathrm{H}), 5.26(\mathrm{~d}, J=7.5 \mathrm{~Hz}$, $1 \mathrm{H}), 4.81(\mathrm{dt}, J=36.0,7.0 \mathrm{~Hz}, 1 \mathrm{H}), 4.70-4.61(\mathrm{~m}, 2 \mathrm{H}), 4.52(\mathrm{dd}, J=12.9,6.3 \mathrm{~Hz}, 1 \mathrm{H}), 4.45-4.27(\mathrm{~m}, 2 \mathrm{H})$, $4.18(\mathrm{t}, J=6.8 \mathrm{~Hz}, 1 \mathrm{H}), 3.86(\mathrm{~d}, J=11.3 \mathrm{~Hz}, 1 \mathrm{H}), 3.78(\mathrm{~s}, 3 \mathrm{H}), 3.25(\mathrm{~d}, J=11.3 \mathrm{~Hz}, 1 \mathrm{H}), 3.03(\mathrm{~m}, 2 \mathrm{H})$, $2.66(\mathrm{~m}, 2 \mathrm{H}), 2.18(\mathrm{t}, J=6.5 \mathrm{~Hz}, 3 \mathrm{H}), 2.15-2.07(\mathrm{~m}, 2 \mathrm{H}), 1.63(\mathrm{~s}, 4 \mathrm{H}) .{ }^{13} \mathrm{C}-\mathrm{NMR}\left(150 \mathrm{MHz}, \mathrm{CDCl}_{3}\right) \delta 172.56$, 169.70, 167.54, 167.03, 162.15, $154.99(\mathrm{~d}, J=11.5 \mathrm{~Hz}), 154.46(\mathrm{~d}, J=14.7 \mathrm{~Hz}), 152.56(\mathrm{~d}, J=74.3 \mathrm{~Hz})$, $147.53(\mathrm{~d}, J=54.5 \mathrm{~Hz}), 144.14,143.09(\mathrm{~d}, J=14.9 \mathrm{~Hz}), 140.69,134.75,128.94,128.73,127.94,127.29$, $127.11,126.50(\mathrm{~d}, J=7.5 \mathrm{~Hz}), 126.07,124.44(\mathrm{~d}, J=7.6 \mathrm{~Hz}), 121.71,119.37,109.04(\mathrm{~d}, J=12.3 \mathrm{~Hz}), 83.92$, $69.32(\mathrm{~d}, J=29.3 \mathrm{~Hz}), 66.25(\mathrm{~d}, J=46.7 \mathrm{~Hz}), 54.26,52.28,46.50,40.89,40.41,37.41,37.18,30.43,23.36$, 22.31. ${ }^{19} \mathrm{~F}-\mathrm{NMR}\left(376 \mathrm{MHz}, \mathrm{CDCl}_{3}\right): \delta-126.27(\mathrm{dd}, J=35.4,21.1 \mathrm{~Hz})$. ESI-MS $(\mathrm{m} / \mathrm{z}): 1059.2[\mathrm{M}+\mathrm{H}]^{+}$. HRMS-ESI $(\mathrm{m} / \mathrm{z})$ : $[\mathrm{M}+\mathrm{Na}]^{+}$calcd. for $\mathrm{C}_{60} \mathrm{H}_{55} \mathrm{FN}_{4} \mathrm{O}_{7} \mathrm{~S}_{3} \mathrm{Na}: 1081.3109$, found: 1081.3126.

(5R,8S,11S/R)-11-((Z)-1-Fluoro-4-(tritylthio)but-1-en-1-yl)-8-isopropyl-5-methyl-10-oxa-3,17-dithia-7,14, 19,20-tetraazatricyclo[14.2.1.12,5]icosa-1(18),2(20),16(19)-triene-6,9,13-trione (14a)

To a solution of 13a $(0.420 \mathrm{~g}, 0.42 \mathrm{mmol})$ in $\mathrm{THF} / \mathrm{H}_{2} \mathrm{O}(4 / 1, \mathrm{v} / \mathrm{v}, 20 \mathrm{~mL}) \mathrm{LiOH} \cdot \mathrm{H}_{2} \mathrm{O}(0.027 \mathrm{~g}$, $0.63 \mathrm{mmol}$ ) was added at $0{ }^{\circ} \mathrm{C}$, and the reaction mixture was stirred for $3 \mathrm{~h}$ at that temperature. After the hydrolysis was completed, the reaction mixture was quenched with $1.0 \mathrm{M} \mathrm{HCl}$ aqueous solution $(1.0 \mathrm{~mL})$, and then extracted with $\mathrm{DCM}(20 \mathrm{~mL} \times 3)$. The combined organic layers were washed successively with water, brine, dried with $\mathrm{Na}_{2} \mathrm{SO}_{4}$ and filtered. After evaporation, the residue was purified by flash chromatography on silica gel, eluting with DCM/MeOH (40/1 to 10/1) to afford the resultant acid $(0.251 \mathrm{~g})$ as a white foamy solid.

The resultant acid $(0.251 \mathrm{~g})$ was dissolved in dry DCM $(20 \mathrm{~mL})$, and $\mathrm{Et}_{2} \mathrm{NH}(1.0 \mathrm{~mL})$ was added at rt. After stirring for $3 \mathrm{~h}$ and removal of the solvent, toluene $(10 \mathrm{~mL})$ was added and evaporated under reduced pressure, and this operation was repeated three times to remove the remaining $\mathrm{Et}_{2} \mathrm{NH}$, affording the crude product.

Then, the crude amino acid was dissolved in dry DCM $(100 \mathrm{~mL})$, and the solution was added dropwise to a stirring solution of HATU $(0.380 \mathrm{~g}, 1.0 \mathrm{mmol})$, HOAT $(0.136 \mathrm{~g}, 1.0 \mathrm{mmol})$, and DIPEA $(0.33 \mathrm{~mL}, 2.0 \mathrm{mmol})$ in DCM $(300 \mathrm{~mL})$ at rt. The reaction mixture was stirred at $\mathrm{rt}$ for $12 \mathrm{~h}$. The solution was concentrated under reduced pressure, and this resultant solution $(100 \mathrm{~mL})$ was washed with saturated $\mathrm{NH}_{4} \mathrm{Cl}$ solution, water, and brine, successively, dried over $\mathrm{Na}_{2} \mathrm{SO}_{4}$, and filtered. After removal of the solvent, the residue was purified by flash chromatography on silica gel, eluting with $\mathrm{PE} / \mathrm{EA} / \mathrm{MeOH}$ $(20 / 20 / 8)$ to afford 14a (31\%, over three steps) as a white foamy solid. $R_{\mathrm{f}}=0.15$ (PE/EA 2/3). $[\alpha]^{20} \mathrm{D}$ -14.3 (c 0.4, $\left.\mathrm{CHCl}_{3}\right) .{ }^{1} \mathrm{H}-\mathrm{NMR}\left(600 \mathrm{MHz}, \mathrm{CDCl}_{3}\right): \delta 7.76(\mathrm{~s}, 1 \mathrm{H}), 7.29(\mathrm{~m}, 15 \mathrm{H}), 7.13(\mathrm{~d}, J=9.2 \mathrm{~Hz}, 1 \mathrm{H})$, $6.41(\mathrm{~d}, J=7.6 \mathrm{~Hz}, 1 \mathrm{H}), 5.60(\mathrm{dd}, J=20.2,10.5 \mathrm{~Hz}, 1 \mathrm{H}), 5.29(\mathrm{dd}, J=17.5,9.7 \mathrm{~Hz}, 1 \mathrm{H}), 5.00(\mathrm{~m}, 1 \mathrm{H})$, $4.62(\mathrm{~d}, J=7.6 \mathrm{~Hz}, 1 \mathrm{H}), 4.20(\mathrm{~d}, J=18.1 \mathrm{~Hz}, 1 \mathrm{H}), 4.04(\mathrm{~d}, J=11.0 \mathrm{~Hz}, 1 \mathrm{H}), 3.28(\mathrm{~d}, J=11.3 \mathrm{~Hz}, 1 \mathrm{H})$, $3.12(\mathrm{~m}, 1 \mathrm{H}), 2.70(\mathrm{~d}, J=16.6 \mathrm{~Hz}, 1 \mathrm{H}), 2.15(\mathrm{~m}, 5 \mathrm{H}), 1.85(\mathrm{~s}, 3 \mathrm{H}), 0.68(\mathrm{~d}, J=6.4 \mathrm{~Hz}, 3 \mathrm{H}), 0.49(\mathrm{~d}, J=6.6 \mathrm{~Hz}$, 3H). ${ }^{13} \mathrm{C}-\mathrm{NMR}\left(150 \mathrm{MHz}, \mathrm{CHCl}_{3}\right): \delta 173.60,168.94,168.76,167.89,164.58,155.25\left(\mathrm{~d},{ }^{1} J_{\mathrm{C}-\mathrm{F}}=256 \mathrm{~Hz}\right)$, $147.49,129.58,127.91,126.65,124.33,109.26\left(\mathrm{~d},{ }^{2} J_{\mathrm{C}-\mathrm{F}}=12.4 \mathrm{~Hz}\right), 84.39,69.95\left(\mathrm{~d},{ }^{3} J_{\mathrm{C}-\mathrm{F}}=29.6 \mathrm{~Hz}\right), 57.58$, $43.32,41.13,38.63,37.49,34.23,31.12,29.72,24.13,22.88,18.84,16.57,14.22 .{ }^{19} \mathrm{~F} \mathrm{NMR}\left(376 \mathrm{MHz}, \mathrm{CDCl}_{3}\right)$ : 
$\delta-124.95(\mathrm{dd}, J=36.2,20.3 \mathrm{~Hz})$. ESI-MS $(\mathrm{m} / \mathrm{z}): 779.4[\mathrm{M}+\mathrm{Na}]^{+}$. HRMS-ESI $(\mathrm{m} / \mathrm{z}):[\mathrm{M}+\mathrm{Na}]^{+}$calcd. for $\mathrm{C}_{40} \mathrm{H}_{41} \mathrm{FN}_{4} \mathrm{O}_{4} \mathrm{~S}_{3} \mathrm{Na}$ : 779.2166, found: 779.2171.

For 14b: $22 \%, R_{\mathrm{f}}=0.15$ (PE/EA 2/3). $[\alpha]^{20}{ }_{\mathrm{D}}:+28.6\left(c 0.021, \mathrm{CHCl}_{3}\right),{ }^{1} \mathrm{H}-\mathrm{NMR}\left(600 \mathrm{MHz}, \mathrm{CDCl}_{3}\right)$ $\delta 7.61(\mathrm{~s}, 1 \mathrm{H}), 7.38(\mathrm{~d}, J=7.6 \mathrm{~Hz}, 6 \mathrm{H}), 7.27(\mathrm{dd}, J=11.0,4.3 \mathrm{~Hz}, 6 \mathrm{H}), 7.20(\mathrm{t}, J=7.3 \mathrm{~Hz}, 3 \mathrm{H}), 7.13(\mathrm{~d}$, $J=7.7 \mathrm{~Hz}, 1 \mathrm{H}), 6.94-6.70(\mathrm{~m}, 5 \mathrm{H}), 6.15(\mathrm{~d}, J=8.3 \mathrm{~Hz}, 1 \mathrm{H}), 5.71(\mathrm{~m}, J=18.9,10.1,1.9 \mathrm{~Hz}, 1 \mathrm{H})$, $5.05(\mathrm{~d}, 12 \mathrm{~Hz}, 1 \mathrm{H}), 5.00(\mathrm{dt}, 36 \mathrm{~Hz}, 7.5 \mathrm{~Hz}, 1 \mathrm{H}), 4.88(\mathrm{~m}, 1 \mathrm{H}), 4.17(\mathrm{dd}, J=17.4,2.8 \mathrm{~Hz}, 1 \mathrm{H}), 4.08(\mathrm{~d}$, $J=11.3 \mathrm{~Hz}, 1 \mathrm{H}), 3.25(\mathrm{~d}, J=11.3 \mathrm{~Hz}, 1 \mathrm{H}), 3.20(\mathrm{dd}, J=14.0,23 \mathrm{~Hz}, 1 \mathrm{H}), 3.06(\mathrm{dd}, J=14.0,5.9 \mathrm{~Hz}, 1 \mathrm{H})$, $2.99(\mathrm{dd}, J=16.4,10.2 \mathrm{~Hz}, 1 \mathrm{H}), 2.62(\mathrm{dd}, J=16.4,2.1 \mathrm{~Hz}, 1 \mathrm{H}), 2.17(\mathrm{dt}, J=11.0,4.0 \mathrm{~Hz}, 2 \mathrm{H}), 2.10(\mathrm{dt}$, $J=14.4,7.2 \mathrm{~Hz}, 2 \mathrm{H}), 1.79(\mathrm{~s}, 3 \mathrm{H}) .{ }^{13} \mathrm{C}-\mathrm{NMR}\left(150 \mathrm{MHz}, \mathrm{CDCl}_{3}\right): \delta 173.67,168.89,168.16,166.97,163.73$, $155.33,153.63,147.26,144.78,135.11,129.60(\mathrm{~d}, J=8.8 \mathrm{~Hz}), 127.88(\mathrm{~d}, J=7.6 \mathrm{~Hz}), 126.65,125.93,123.68$, $109.17(\mathrm{~d}, J=12.5 \mathrm{~Hz}), 84.19,70.18(\mathrm{~d}, J=30.9 \mathrm{~Hz}), 66.61,54.19,42.46,40.98,37.70,37.46,31.12,24.98$, $22.88(\mathrm{~d}, J=3.8 \mathrm{~Hz}) .{ }^{19} \mathrm{~F}-\mathrm{NMR}\left(376 \mathrm{MHz}, \mathrm{CDCl}_{3}\right): \delta-124.43(\mathrm{dd}, J=36.2,20.3 \mathrm{~Hz})$. ESI-MS $(\mathrm{m} / \mathrm{z}): 827.2$ $[\mathrm{M}+\mathrm{Na}]^{+}$. HRMS-ESI $(\mathrm{m} / \mathrm{z})$ : $[\mathrm{M}+\mathrm{Na}]^{+}$calcd. for $\mathrm{C}_{44} \mathrm{H}_{41} \mathrm{FN}_{4} \mathrm{O}_{4} \mathrm{~S}_{3} \mathrm{Na}$ : 827.2166, found: 827.2166.

(5R,8S,11S/R)-11-((Z)-1-Fluoro-4-mercaptobut-1-en-1-yl)-8-isopropyl-5-methyl-10-oxa-3,17-dithia-7,14,19, 20-tetraazatricyclo[14.2.1.12,5]icosa-1(18),2(20),16(19)-triene-6,9,13-trione (15a)

14a $(50 \mathrm{mg}, 0.066 \mathrm{mmol})$ was dissolved in dry DCM $(15 \mathrm{~mL})$ and cooled to $0{ }^{\circ} \mathrm{C}$. The mixture was successively treated with $\mathrm{Et}_{3} \mathrm{SiH}(27 \mu \mathrm{L}, 0.13 \mathrm{mmol})$ and TFA $(0.30 \mathrm{~mL}, 4.0 \mathrm{mmol})$. The reaction mixture was allowed to warm to room temperature and stirred for $1.5 \mathrm{~h}$ before being concentrated and chromatographed (EtOAc) to provide a clear oil $(15 \mathrm{mg}, 0.03 \mathrm{mmol})$. The reaction was quenched with a saturated $\mathrm{NaHCO}_{3}$ solution $(10 \mathrm{~mL})$ and separated. The aqueous phase was extracted with $\mathrm{DCM}(10 \mathrm{~mL} \times 3)$, and the combined layers were washed with brine, dried over $\mathrm{Na}_{2} \mathrm{SO}_{4}$, and filtered. After removal of the solvent, the residue was purified by flash chromatography on silica gel, eluting with DCM/EA (1/1) to afford 15a in 67\% yield as a white foamy solid. $R_{\mathrm{f}}=0.42(\mathrm{PE} / \mathrm{EA} 2 / 3) .{ }^{1} \mathrm{H}-\mathrm{NMR}$ $\left(600 \mathrm{MHz}, \mathrm{CDCl}_{3}\right): \delta 7.78(\mathrm{~s}, 1 \mathrm{H}), 7.14(\mathrm{~d}, J=9.5 \mathrm{~Hz}, 1 \mathrm{H}), 6.51(\mathrm{~d}, J=7.3 \mathrm{~Hz}, 1 \mathrm{H}), 5.67(\mathrm{dd}, J=20.2$, $11.0 \mathrm{~Hz}, 1 \mathrm{H}), 5.32(\mathrm{dd}, J=17.5,9.7 \mathrm{~Hz}, 2 \mathrm{H}), 5.15(\mathrm{dt}, J=36.5,7.5 \mathrm{~Hz}, 1 \mathrm{H}), 4.65(\mathrm{dd}, J=9.4,3.2 \mathrm{~Hz}, 1 \mathrm{H})$, $4.26(\mathrm{dd}, J=17.5,2.8 \mathrm{~Hz}, 1 \mathrm{H}), 4.05(\mathrm{~d}, J=11.4 \mathrm{~Hz}, 1 \mathrm{H}), 3.30(\mathrm{~d}, J=11.4 \mathrm{~Hz}, 1 \mathrm{H}), 3.17(\mathrm{~m}, 2 \mathrm{H}), 2.76(\mathrm{~d}$, $J=16.4 \mathrm{~Hz}, 1 \mathrm{H}), 2.56(\mathrm{~m}, 3 \mathrm{H}), 2.42(\mathrm{~m}, 2 \mathrm{H}), 2.15(\mathrm{~m}, 5 \mathrm{H}), 1.87(\mathrm{~s}, 3 \mathrm{H}), 0.69(\mathrm{~d}, J=6.9 \mathrm{~Hz}, 3 \mathrm{H}), 0.50(\mathrm{~d}$, $J=6.8 \mathrm{~Hz}, 3 \mathrm{H})$. ESI-MS (m/z): $515.2[\mathrm{M}+\mathrm{H}]^{+}$. HRMS-ESI $(\mathrm{m} / \mathrm{z}):[\mathrm{M}+\mathrm{H}]^{+}$calcd. for $\mathrm{C}_{21} \mathrm{H}_{27} \mathrm{FN}_{4} \mathrm{O}_{4} \mathrm{~S}_{3} \mathrm{H}$ : 515.1251, found: 515.1252 .

For 15b: 59\%, $R_{\mathrm{f}}=0.42(\mathrm{PE} / \mathrm{EA} 2 / 3) .{ }^{1} \mathrm{H}-\mathrm{NMR}\left(600 \mathrm{MHz}, \mathrm{CDCl}_{3}\right) \delta 7.66(\mathrm{~s}, 1 \mathrm{H}), 7.19(\mathrm{~m}, 2 \mathrm{H})$, $6.84(\mathrm{~m}, 5 \mathrm{H}), 6.15(\mathrm{~s}, 1 \mathrm{H}), 5.78(\mathrm{dd}, J=17.9,9.4 \mathrm{~Hz}, 1 \mathrm{H}), 5.16(\mathrm{dt}, J=36.3,7.5 \mathrm{~Hz}, 1 \mathrm{H}), 5.04(\mathrm{dd}, J=17.4$, $8.2 \mathrm{~Hz}, 1 \mathrm{H}), 4.93(\mathrm{~m}, 1 \mathrm{H}), 4.27(\mathrm{~d}, J=17.1 \mathrm{~Hz}, 1 \mathrm{H}), 4.11(\mathrm{~d}, J=11.2 \mathrm{~Hz}, 1 \mathrm{H}), 3.26(\mathrm{~d}, J=11.3 \mathrm{~Hz}, 1 \mathrm{H})$, $3.22(\mathrm{dd}, J=14.0,3.0 \mathrm{~Hz}, 1 \mathrm{H}), 3.12-3.08(\mathrm{~m}, 1 \mathrm{H}), 3.07(\mathrm{~d}, J=5.9 \mathrm{~Hz}, 1 \mathrm{H}), 2.67(\mathrm{~d}, J=14.8 \mathrm{~Hz}, 1 \mathrm{H}), 2.54(\mathrm{dd}$, $J=14.4,7.1 \mathrm{~Hz}, 1 \mathrm{H}), 2.40(\mathrm{~m}, 2 \mathrm{H}), 1.83(\mathrm{~s}, 3 \mathrm{H})$. ESI-MS $(\mathrm{m} / \mathrm{z}): 563.0[\mathrm{M}+\mathrm{H}]^{+}$. HRMS-ESI $(\mathrm{m} / \mathrm{z}):[\mathrm{M}+\mathrm{H}]^{+}$ calcd. for $\mathrm{C}_{25} \mathrm{H}_{27} \mathrm{FN}_{4} \mathrm{O}_{4} \mathrm{~S}_{3} \mathrm{H}$ : 563.1251, found: 563.1254.

S-((Z)-4-Fluoro-4-((5R,8S,11S/R)-8-isopropyl-5-methyl-6,9,13-trioxo-10-oxa-3,17-dithia-7,14,19,20-tetra azatricyclo[14.2.1.12,5]icosa-1(18),2(20),16(19)-trien-11-yl)but-3-en-1-yl) octanethioate (16a)

The free thiol 15a $(26 \mathrm{mg})$ was dissolved in dry DCM $(10 \mathrm{~mL})$ and cooled to $0{ }^{\circ} \mathrm{C}$. The mixture was successively treated with $\mathrm{Et}_{3} \mathrm{~N}(14 \mu \mathrm{L}, 0.1 \mathrm{mmol})$ and octanoyl chloride $(42 \mu \mathrm{L}, 0.25 \mathrm{mmol})$. The reaction was allowed to warm to rt and stirred for $2 \mathrm{~h}$, and then quenched with a saturated $\mathrm{NaHCO}_{3}$ solution $(10 \mathrm{~mL})$ and separated. The aqueous phase was extracted with DCM $(10 \mathrm{~mL} \times 3)$, and the combined layers were washed successively with brine, dried over $\mathrm{Na}_{2} \mathrm{SO}_{4}$, and filtered. After removal of the solvent, the residue was purified by flash chromatography on silica gel, eluting with DCM/EA (1/1) to afford $16 \mathrm{a}(61 \%)$ as a white foamy solid. $R_{\mathrm{f}}=0.42$ (DCM/EA 3/1). $[\alpha]^{20}{ }_{\mathrm{D}}:+34.3\left(c 0.3, \mathrm{CHCl}_{3}\right) .{ }^{1} \mathrm{H}-\mathrm{NMR}$ $\left(600 \mathrm{MHz}, \mathrm{CDCl}_{3}\right): \delta 7.78(\mathrm{~s}, 1 \mathrm{H}), 7.13(\mathrm{~d}, J=9.5 \mathrm{~Hz}, 1 \mathrm{H}), 6.42(\mathrm{~d}, J=7.8 \mathrm{~Hz}, 1 \mathrm{H}), 5.65(\mathrm{~m}, 1 \mathrm{H}), 5.32(\mathrm{dd}$, $J=17.5,9.8 \mathrm{~Hz}, 1 \mathrm{H}), 5.10(\mathrm{dt}, J=7.2,2 \mathrm{~Hz}, 1 \mathrm{H}), 4.65(\mathrm{dd}, J=9.3,2.9 \mathrm{~Hz}, 1 \mathrm{H}), 4.26(\mathrm{dd}, J=17.5,2.8 \mathrm{~Hz}$, $1 \mathrm{H}), 4.05(\mathrm{~d}, J=11.3 \mathrm{~Hz}, 1 \mathrm{H}), 3.28(\mathrm{~d}, J=11.3 \mathrm{~Hz}, 1 \mathrm{H}), 3.16(\mathrm{dd}, J=16.4,11.4 \mathrm{~Hz}, 1 \mathrm{H}), 2.90(\mathrm{t}, J=7.1 \mathrm{~Hz}$, $2 \mathrm{H}), 2.74(\mathrm{~d}, J=14.8 \mathrm{~Hz}, 1 \mathrm{H}), 2.54(\mathrm{t}, J=7.5 \mathrm{~Hz}, 2 \mathrm{H}), 2.37(\mathrm{~m}, 2 \mathrm{H}), 2.13(\mathrm{~m}, 1 \mathrm{H}), 1.88(\mathrm{~s}, 3 \mathrm{H}), 1.65(\mathrm{~m}$, 
2H), $1.28(\mathrm{~m}, 8 \mathrm{H}), 0.88(\mathrm{~m}, 3 \mathrm{H}), 0.68(\mathrm{~d}, J=6.7 \mathrm{~Hz}, 3 \mathrm{H}), 0.49(\mathrm{~d}, J=6.7 \mathrm{~Hz}, 3 \mathrm{H}) .{ }^{13} \mathrm{C}-\mathrm{NMR}(150 \mathrm{MHz}$, $\left.\mathrm{CDCl}_{3}\right): \delta 199.35,173.64,168.96,168.84,167.90,164.62,155.25(\mathrm{~d}, J=256 \mathrm{~Hz}), 147.49,124.41,108.71(\mathrm{~d}$, $J=12.6 \mathrm{~Hz}), 84.40,69.95(\mathrm{~d}, J=29.6 \mathrm{~Hz}), 57.54,44.17,43.35,41.17,37.47,34.33,31.63,28.92,27.9,25.64$, 24.13, 23.86, 22.61, 18.86, 16.51, 14.09. ${ }^{19} \mathrm{~F} \mathrm{NMR}\left(376 \mathrm{MHz}, \mathrm{CDCl}_{3}\right): \delta-124.76$ (dd, $\left.J=35.9,20.9 \mathrm{~Hz}\right)$. ESI-MS $(\mathrm{m} / \mathrm{z}): 663.3[\mathrm{M}+\mathrm{Na}]^{+}$. HRMS-ESI $(\mathrm{m} / \mathrm{z}):[\mathrm{M}+\mathrm{Na}]^{+}$calcd. for $\mathrm{C}_{40} \mathrm{H}_{41} \mathrm{FN}_{4} \mathrm{O}_{4} \mathrm{~S}_{3} \mathrm{Na}: 663.2115$, found: 663.2139 .

For 16b: 66\%, $R_{\mathrm{f}}=0.42(\mathrm{DCM} / \mathrm{EA} 3 / 1) .[\alpha]^{20} \mathrm{D}:+36.6\left(c 0.025, \mathrm{CHCl}_{3}\right) .{ }^{1} \mathrm{H}-\mathrm{NMR}(150 \mathrm{MHz}$, $\left.\mathrm{CDCl}_{3}\right) \delta 7.64(\mathrm{~s}, 1 \mathrm{H}), 7.14(\mathrm{~d}, J=7.7 \mathrm{~Hz}, 2 \mathrm{H}), 7.00-6.74(\mathrm{~m}, 5 \mathrm{H}), 6.15(\mathrm{~d}, J=8.0 \mathrm{~Hz}, 1 \mathrm{H}), 5.76(\mathrm{dd}$, $J=19.2,9.9 \mathrm{~Hz}, 1 \mathrm{H}), 5.12(\mathrm{dt}, J=36.3 \mathrm{~Hz}, 7.5 \mathrm{~Hz}, 1 \mathrm{H}), 5.06(\mathrm{~d}, J=9.0 \mathrm{~Hz}, 1 \mathrm{H}), 4.92(\mathrm{t}, J=8.1 \mathrm{~Hz}, 1 \mathrm{H})$, $4.92(\mathrm{t}, J=8.1 \mathrm{~Hz}, 1 \mathrm{H}), 4.24(\mathrm{dd}, J=17.4,2.1 \mathrm{~Hz}, 1 \mathrm{H}), 4.10(\mathrm{~d}, J=11.2 \mathrm{~Hz}, 1 \mathrm{H}), 3.23(\mathrm{~d}, J=11.2 \mathrm{~Hz}, 1 \mathrm{H})$, $3.21(\mathrm{~d}, J=2.8 \mathrm{~Hz}, 1 \mathrm{H}), 3.06(\mathrm{~m}, 2 \mathrm{H}), 2.88(\mathrm{t}, J=7.1 \mathrm{~Hz}, 2 \mathrm{H}), 2.66(\mathrm{~d}, J=16.0 \mathrm{~Hz}, 1 \mathrm{H}), 2.53(\mathrm{t}, J=7.5 \mathrm{~Hz}$, $2 \mathrm{H}), 2.36(\mathrm{dd}, J=14.4,7.2 \mathrm{~Hz}, 2 \mathrm{H}), 1.83(\mathrm{~s}, 3 \mathrm{H}), 1.64(\mathrm{dd}, J=14.0,7.0 \mathrm{~Hz}, 3 \mathrm{H}), 1.27(\mathrm{~m}, 8 \mathrm{H}), 0.89(\mathrm{dd}$, $J=9.0,4.6 \mathrm{~Hz}, 3 \mathrm{H}) .{ }^{13} \mathrm{C}-\mathrm{NMR}\left(150 \mathrm{MHz}, \mathrm{CDCl}_{3}\right): \delta 198.61,173.12,168.27,167.47,166.35,163.04$, $146.63(\mathrm{~d}, J=28.5 \mathrm{~Hz}), 134.52,129.03,127.22,125.29,123.03,107.82(\mathrm{~d}, J=23.4 \mathrm{~Hz}), 83.63,69.52(\mathrm{~d}$, $J=30.9 \mathrm{~Hz}), 53.57,43.52,41.84,40.37,37.00(\mathrm{~d}, J=18.3 \mathrm{~Hz}), 30.98,29.07,28.27,27.27,24.99,24.35,23.20$, 21.95, $13.45(\mathrm{~d}, J=8.6 \mathrm{~Hz}) .{ }^{19} \mathrm{~F}-\mathrm{NMR}\left(376 \mathrm{MHz}, \mathrm{CDCl}_{3}\right): \delta-124.76(\mathrm{dd}, J=36.1,19.3 \mathrm{~Hz})$. ESI-MS $(\mathrm{m} / \mathrm{z})$ : $689.2[\mathrm{M}+\mathrm{H}]^{+}$. HRMS-ESI $(\mathrm{m} / \mathrm{z}):[\mathrm{M}+\mathrm{H}]^{+}$calcd. for $\mathrm{C}_{33} \mathrm{H}_{41} \mathrm{FN}_{4} \mathrm{O}_{5} \mathrm{~S}_{3}: 689.2296$, found: 689.2302.

\subsection{Biological Evaluation}

\subsubsection{Recombinant Human HDAC1, HDAC2, HDAC3, HDAC6, and HDAC8 Enzymatic Assays}

The assays were carried out by Shanghai ChemPartner Co., Ltd. (Shanghai, China). Briefly, different concentrations of compounds were incubated with recombinant human HDAC1, HDAC2, HDAC3, HDAC6, and HDAC8 (BPS Biosciences, San Diego, CA, USA) at room temperature for $15 \mathrm{~min}$, which was followed by adding Ac-peptide-AMC substrates to initiate the reaction in Tris-based assay buffer. Reaction mixtures were incubated at room temperature for $60 \mathrm{~min}$ in the HDAC1, HDAC2, HDAC3, and HDAC6 assays, and were incubated for $240 \mathrm{~min}$ in the HDAC8 assay. Then a stop solution containing trypsin was added. The coupled reaction was incubated for another $90 \mathrm{~min}$ at $37^{\circ} \mathrm{C}$. Fluorescent AMC released from substrate was measured in SynergyMx (BioTek, Winooski, VT, USA) using filter sets as excitation $=355 \mathrm{~nm}$ and emission $=460 \mathrm{~nm}$. $\mathrm{IC}_{50}$ values were calculated by GraphPad Prism version 4.00 Windows (GraphPad Software, San Diego, CA, USA).

3.2.2. Cytotoxic Effect Tested by 3-(4,5-Dimethylthiazol-2-yl)-2,5-Diphenyltetrazolium Bromide (MTT) Assay

The MTT assay was used to determine the cytotoxic effect of these compounds on A549, HCT116, MDA-MB-231, and SK-OV-3 tumor cells. Cells (600,000 cells/well) were seeded in 96-well plates and incubated for $24 \mathrm{~h}$ before being treated with various concentrations of compounds or solvent control. Cells were further incubated for $72 \mathrm{~h}$ and then treated with MTT and incubated for another $3 \mathrm{~h}$. The media were then removed and $100 \mu \mathrm{L}$ DMSO was added to each well. The absorbance at 550 nm was measured by a SpectraMAX340 microplate reader (Molecular Devices, Sunnyvale, CA, USA) with a reference wavelength at $690 \mathrm{~nm}$. Largazole was used as a positive control in the assay.

\section{Conclusions}

Largazole and Psammaplin A, two marine natural products belonging to a family of sulfur-containing natural products with potent HDAC inhibitory activities, contain the similar side chain unit. Inspired by the structural similarity, we hypothesized the fluoro olefin moiety would mimic both the alkene moiety in Largazole and amide moiety in Psammaplin A, and thus designed and synthesized two novel fluoro olefin analogs of Largazole. The preliminary biological assays showed that the fluoro analogs possessed comparable Class I HDAC inhibitory activities, indicating that this kind of modification on the side chain of Largazole was tolerable. 
Supplementary Materials: The supporting information is available online at http://www.mdpi.com/1660-3397/17/6/ 333/s1.

Author Contributions: B.Z. and G.S. performed the chemical research and analyzed the data. X.Y., Z.-W.R. and Y.L. participated in the research. X.L. was responsible for the funding of project, the design of the research and the writing of the manuscript. All authors read and approved the final manuscript.

Funding: This research was funded by National Key Research and Development Program of China (No. 2018YFC0310906) and National Natural Science Foundation of China (No. 21472024 and No. 21242008).

Acknowledgments: The authors acknowledge National Key Research and Development Program of China and National Natural Science Foundation of China for the financial support. The authors also acknowledge Tan Wen-Fu for the cellular assays and Shanghai ChemPartner Co., Ltd. for the HDAC inhibition assays. The authors are grateful to Jie-Fei Cheng for his helpful discussion.

Conflicts of Interest: The authors declare no conflict of interest.

\section{References}

1. Delcuve, G.P.; Khan, D.H.; Davie, J.R. Roles of histone deacetylases in epigenetic regulation: Emerging paradigms from studies with inhibitors. Clin. Epigenet. 2012, 4, 5-17. [CrossRef] [PubMed]

2. De Ruijter, A.J.; Van Gennip, A.H.; Caron, H.N.; Kemp, S.; Van Kuilenburg, A.B. Histone deacetylases (HDACs): Characterization of the classical HDAC family. Biochem. J. 2003, 370, 737-749. [CrossRef] [PubMed]

3. Johnstone, R.W. Histone-deacetylase inhibitors: Novel drugs for the treatment of cancer. Nat. Rev. Drug Discov. 2002, 1, 287-299. [CrossRef] [PubMed]

4. Emanuele, S.; Lauricella, M.; Tesoriere, G. Histone deacetylase inhibitors: Apoptotic effects and clinical implications. Int. J. Oncol. 2008, 33, 637-646. [CrossRef] [PubMed]

5. Roche, J.; Bertrand, P. Inside HDACs with more selective HDAC inhibitors. Eur. J. Med. Chem. 2016, 121, 451-483. [CrossRef] [PubMed]

6. Balasubramanian, S.; Verner, E.; Buggy, J.J. Isoform-specific histone deacetylase inhibitors: The next step? Cancer Lett. 2009, 280, 211-221. [CrossRef] [PubMed]

7. Tabackman, A.A.; Frankson, R.; Marsan, E.S.; Perry, K.; Cole, K.E. Structure of 'linkerless' hydroxamic acid inhibitor-HDAC8 complex confirms the formation of an isoform-specific subpocket. J. Struct. Biol. 2016, 195, 373-378. [CrossRef] [PubMed]

8. Taori, K.; Paul, V.J.; Luesch, H. Structure and activity of largazole, a potent antiproliferative agent from the Floridian marine cyanobacterium Symploca sp. J. Am. Chem. Soc. 2008, 130, 1806-1807. [CrossRef] [PubMed]

9. Ying, Y.; Taori, K.; Kim, H.; Hong, J.; Hendrik Luesch, H. Total Synthesis and Molecular Target of Largazole, a Histone Deacetylase Inhibitor. J. Am. Chem. Soc. 2008, 130, 8455-8459. [CrossRef]

10. Bowers, A.; West, N.; Taunton, J.; Schreiber, S.L.; Bradner, J.E.; Williams, R.M. Thiophene-derivatized Fluorescent Benzamides as Possible Probes for Histone Deacetylases. J. Am. Chem. Soc. 2008, 130, 11219-11222. [CrossRef]

11. Maolanon, A.R.; Kristensen, H.M.E.; Leman, L.J.; Ghadiri, M.R.; Olsen, C.A. Natural and synthetic macrocyclic inhibitors of the histone deacetylase enzymes. ChemBioChem 2017, 18, 5-49. [CrossRef]

12. Reddy, D.N.; Ballante, F.; Chuang, T.; Pirolli, A.; Marrocco, B.; Marshall, G.R. Design and Synthesis of Simplified Largazole Analogues as Isoform-Selective Human Lysine Deacetylase Inhibitors. J. Med. Chem. 2016, 59, 1613-1633. [CrossRef] [PubMed]

13. Yao, Y.; Tu, Z.; Liao, C.; Wang, Z.; Li, S.; Yao, H.; Li, Z.; Jiang, S. Discovery of novel class I histone deacetylase inhibitors with promising in vitro and in vivo antitumor activities. J. Med. Chem. 2015, 58, 7672-7680. [CrossRef] [PubMed]

14. Clausen, D.J.; Smith, W.B.; Haines, B.E.; Wiest, O.; Bradner, J.E.; Williams, R.M. Modular synthesis and biological activity of pyridyl-based analogs of the potent Class i Histone Deacetylase Inhibitor Largazole. Bioorg. Med. Chem. 2015, 23, 5061-5074. [CrossRef] [PubMed]

15. Ueda, H.; Nakajima, H.; Hori, Y.; Fujita, T.; Nishimura, M.; Goto, T.; Okuhara, M.J. Action of FR901228, a novel antitumor bicyclic depsipeptide produced by Chromobacterium violaceum no. 968, on Ha-ras transformed NIH3T3 cells. Biosci. Biotechnol. Biochem. 1994, 58, 1579-1583. [CrossRef] [PubMed]

16. Shigematsu, N.; Ueda, H.; Takase, S.; Tanaka, H.J. FR901228, a novel antitumor bicyclic depsipeptide produced by Chromobacterium violaceum No. 968. J. Antibiot. 1994, 47, 311-314. [CrossRef] [PubMed] 
17. Ueda, H.; Manda, T.; Matsumoto, S.; Mukumoto, S.; Nishigaki, F.; Kawamura, I.; Shimomura, K.J. FR901228, a novel antitumor bicyclic depsipeptide produced by Chromobacterium violaceum No. 968. III. Antitumor activities on experimental tumors in mice. J. Antibiot. 1994, 47, 315-323. [CrossRef]

18. Masuoka, Y.; Nagai, A.; Shin-ya, K.; Furihata, K.; Nagai, K.; Suzuki, K.; Hayakawa, Y.; Seto, H. Spiruchostatins A and B, novel gene expression-enhancing substances produced by Pseudomonas sp. Tetrahedron Lett. 2001, 42, 411-444. [CrossRef]

19. Baud, M.G.J.; Leiser, T.; Haus, P.; Samlal, S.; Wong, A.C.; Wood, R.J.; Petrucci, V.; Gunaratnam, M.; Hughes, S.M.; Buluwela, L.; et al. Defining the mechanism of action and enzymatic selectivity of psammaplin A against its epigenetic targets. Med. Chem. 2012, 55, 1731-1750. [CrossRef]

20. Poli, G.; Fabio, R.D.; Ferrante, L.; Summa, V.; Botta, M. Largazole Analogues as Histone Deacetylase Inhibitors and Anticancer Agents: An Overview of Structure-Activity Relationships. ChemMedChem 2017, 12, 1917-1926. [CrossRef]

21. Ying, Y.; Liu, Y.; Byeon, S.R.; Kim, H.; Luesch, H.; Hong, J. Synthesis and activity of largazole analogues with linker and macrocycle modification. Org. Lett. 2008, 10, 4021-4024. [CrossRef] [PubMed]

22. Zeng, X.; Yin, B.; Hu, Z.; Liao, C.; Liu, J.; Li, S.; Li, Z.; Nicklaus, M.C.; Zhou, G.; Jiang, S. Total synthesis and biological evaluation of largazole and derivatives with promising selectivity for cancers cells. Org. Lett. 2010, 12, 1368-1371. [CrossRef] [PubMed]

23. Bowers, A.A.; West, N.; Newkirk, T.L.; Troutman-Youngman, A.E.; Schreiber, S.L.; Wiest, O.; Bradner, J.E.; Williams, R.M. Synthesis and histone deacetylase inhibitory activity of largazole analogs: Alteration of the zinc-binding domain and macrocyclic scaffold. Org. Lett. 2009, 11, 1301-1304. [CrossRef] [PubMed]

24. Bhansali, P.; Hanigan, C.L.; Casero, R.A.; Tillekeratne, L.M. Largazole and analogues with modified metal-binding motifs targeting histone deacetylases: Synthesis and biological evaluation. J. Med. Chem. 2011, 54, 7453-7463. [CrossRef] [PubMed]

25. Kim, B.; Park, H.; Salvador, L.A.; Serrano, P.E.; Kwan, J.C.; Zeller, S.L.; Chen, Q.Y.; Ryu, S.; Liu, Y.; Byeon, S.; et al. Evaluation of class I HDAC isoform selectivity of largazole analogues. Bioorg. Med. Chem. Lett. 2014, 24, 3728-3731. [CrossRef]

26. Kim, B.; Ratnayake, R.; Lee, H.; Shi, G.; Zeller, S.L.; Li, C.; Luesch, H.; Hong, J. Synthesis and biological evaluation of largazole zinc-binding group analogs. Bioorg. Med. Chem. 2017, 25, 3077-3086. [CrossRef]

27. Cole, K.E.; Dowling, D.P.; Boone, M.A.; Phillips, A.J.; Christianson, D.W. Structural basis of the antiproliferative activity of largazole, a depsipeptide inhibitor of the histone deacetylases. J. Am. Chem. Soc. 2011, 133, 12474-12477. [CrossRef]

28. Yu, X.; Zhang, B.; Shan, G.; Wu, Y.; Yang, F.-L.; Lei, X. Synthesis of the molecular hybrid inspired by Largazole and Psammaplin A. Tetrahedron 2018, 74, 549-555. [CrossRef]

29. Couve-Bonnaire, S.; Cahard, D.; Pannecoucke, X. Chiral dipeptide mimics possessing a fluoroolefin moiety: A relevant tool for conformational and medicinal studies. Org. Biomol. Chem. 2007, 5, 1151-1157. [CrossRef]

30. Zoute, L.; Dutheuil, G.; Quirion, J.C.; Jubault, P.; Pannecoueke, X. Efficient Synthesis of Fluoroalkenes via Diethylzinc-Promoted Wittig Reaction. Synthesis 2006, 2006, 3409-3418. [CrossRef]

31. Nagao, Y.; Hagiwara, Y.; Kumagai, T.; Ochiai, M.; Inoue, T.; Hashimoto, K.; Fujita, E. New C4-Chiral 1,3-Thiazolidine-2-thiones: Excellent Chiral Auxiliaries for Highly Diastereocontrolled Aldol-Type Reactions of Acetic Acid and $\alpha, \beta$-Unsaturated Aldehydes. J. Org. Chem. 1986, 51, 2391-2393. [CrossRef]

32. Xiao, Q.; Wang, L.-P.; Jiao, X.-Z.; Liu, X.-Y.; Wu, Q.; Xie, P. Concise total synthesis of largazole. J. Asian Nat. Prod. Res. 2010, 12, 940-949. [CrossRef] [PubMed]

33. Chen, F.; Chai, H.; Su, M.-B.; Zhang, Y.-M.; Li, J.; Xie, X.; Nan, F.-J. Potent and orally efficacious bisthiazole-based histone deacetylase inhibitors. ACS Med. Chem. Lett. 2014, 5, 628-633. [CrossRef] [PubMed]

34. Hong, J.; Luesch, H. Largazole: From discovery to broad-spectrum therapy. Nat. Prod. Rep. 2012, 29 , 449-456. [CrossRef] [PubMed]

(C) 2019 by the authors. Licensee MDPI, Basel, Switzerland. This article is an open access article distributed under the terms and conditions of the Creative Commons Attribution (CC BY) license (http://creativecommons.org/licenses/by/4.0/). 